\title{
Borsa İstanbul'da işlem gören savunma sanayi şirketlerinin Bulanık TOPSİS yöntemi ile finansal performans analizi ${ }^{1}$ Financial performance analysis of defence industry companies in Borsa Istanbul with Fuzzy TOPSIS method
}

\author{
Serdar Ögel ${ }^{2}$ \\ Kerim Nuryyev ${ }^{3}$
}

\begin{abstract}
${ }^{1}$ Bu çalışma Afyon Kocatepe Üniversitesi Sosyal Bilimler Enstitüsü'nde Dr. Öğr. Üyesi Serdar ÖGEL tarafından yürütülen ve Kerim NURYYEV tarafindan hazırlanan ve 2020 y1lında sunulan “Borsa İstanbul'da İşlem Gören Savunma Sanayi Şirketlerinin Finansal Performans Analizi" başlıklı yüksek lisans tezinden üretilmiştir
\end{abstract}

${ }^{2}$ Dr. Öğr. Üyesi, Afyon Kocatepe Üniversitesi, İ̈BF, İşletme Bölümü, Afyonkarahisar, Türkiye, serdarogel@aku.edu.tr

ORCID: 0000-0002-7151-1671

${ }^{3}$ Yüksek Lisans Öğrencisi, Afyon Kocatepe Üniversitesi, Sosyal Bilimler Enstitüsü, İşletme Anabilim Dalı, Afyonkarahisar, Türkiye, kerimnuryyev@hotmail.com

ORCID 0000-0001-8268-153X

\section{Sorumlu Yazar/Corresponding Author:}

Serdar Ögel,

Afyon Kocatepe Üniversitesi, İİBF, İşletme Bölümü, Afyonkarahisar, Türkiye, serdarogel@aku.edu.tr

Başvuru/Submitted: 25/01/2021

Revizyon/Revised: 5/03/2021

Kabul/Accepted: 11/03/2021

Yayın/Online Published: 25/03/2021

Atıf/Citation: Ögel, S., \& Nuryyev, K., Borsa İstanbul' da işlem gören savunma sanayi şirketlerinin Bulanık TOPSís yöntemi ile finansal performans analizi, bmij (2021) 9 (1): 307-326, doi:

https://doi.org/10.15295/bmij.v9i1.1780
Öz

Türkiye'deki savunma sanayi sektöründe faaliyet gösteren şirketler, temel amacı olan kar elde edebilmenin yanında Türk Silahlı Kuvvetlerine tamamen yerli ve milli savunma teçhizatları sağlayabilme ile beraberinde hem ulusal hem de küresel anlamda daha rekabetçi olabilmek için finansal performanslarını yükseltmeleri gerekmektedir. Performanslarının yüksek olması yerel ve uluslararası pazarlarda büyük önem taşımaktadır. Bu çalışmada, hisse senetleri Borsa İstanbul (BİST)'da kote olmus savunma sanayi şirketlerinin finansal tabloları kullanılarak finansal oranları belirlenmiştir. Bu veriler doğrultusunda karar kriterleri ve bu karar kriterlerine göre alanlarında tecrübeli 7 uzman tarafından dilsel değişkenler yardımı ile değerlendirilmiştir. Uzmanlardan elde edilen veriler üçgen bulanık sayı sistemine dönüştürülmüş ve Bulanık TOPSIS (Technique for Order Preference by Smilarity to Ideal Solution) yöntemi uygulanmıştır. Savunma sanayi şirketleri yakınlık katsayılarına göre en iyiden en kötüye doğru sıralanmıştır.

Anahtar Kelimeler: Bulanık TOPSIS, Savunma Sanayi, Finansal Performans, Borsa İstanbul (BİST)

Jel Sinıflandırması: C30, E44, L25, D53

\begin{abstract}
Companies operating in Turkey's defence industry sector need to improve their financial performance to be more competitive both nationally and globally. The ability to provide the Turkish Armed Forces with fully domestic and national defence equipment in making a profit is their primary objective. High performance should be of great importance in local and international markets. In this study, the financial ratios of the companies operating in the defense industry sector, whose stocks are traded in Borsa Istanbul (BIST), are determined by using the financial statements. According to decision criteria and these decision criteria, linguistic variables were evaluated by seven experts in line with these data. The experts' data were triangular fuzzy number system, and the Fuzzy TOPSIS (Technique for Order Preference by Similarity to Ideal Solution) method was applied. Defence industry companies are ranked from best to worst according to their near coefficients.
\end{abstract}

Keywords: Fuzzy TOPSIS, Defense Industry, Financial Performance, Borsa Istanbul (BIST)

Jel Codes: C30, E44, L25, D53 


\section{Extended Abstract}

\section{Financial performance analysis of defence industry companies in Borsa Istanbul with Fuzzy TOPSIS method}

\section{Literature}

The defence industry is one of the critical industries for countries' future in terms of its contributions to the armed forces, economic growth and development of the countries and other relevant industries such as iron, steel, glass, automotive and electric and electronic. In the relevant literature, there are several academic studies on defence industry concerning social and economic effects of defence expenditure (Değer, 1986); effects of defence planning (Topçu,2010) and defence industry (Temiz, 2012) on the economy; the interaction between defence industry, globalisation and crises (Şişman, 2007); innovation approach of companies operating in the defence industry (Konukbay, 2016); situation analysis of Turkish defence industry (Yeşilyurt and Yeşilyurt, 2019); the place and importance of uncrewed air vehicles in defence industry expenditures (Bakır, 2019) and the relationship between terrorist attacks and defence industry (Topal,2020). On the other hand, several empirical types of research adopt the TOPSIS method to examine the financial performance of companies traded in BIST and operating in the technology industry (Demirhan and Aracıoğlu, 2017); automotive industry (Kayalı and Aktaş, 2018; Tezcan, 2019); cement industry (Saygilı and Şahin, 2018); tourism industry (Bilici, 2019) and finance industry (Özçelik and Küçükçakal, 2019). Nevertheless, no empirical research examines the financial performance of defence industry companies traded in BIST with the fuzzyTOPSIS method. Thus, this study examines the financial performance of defence industry companies traded in BIST by adopting the fuzzy TOPSIS method. It is expected that the findings of the study will contribute to the literature by fulfilling the research gap and the development of the defence industry in Turkey.

\section{Design And Method}

This study which aims to examine the financial performance of defence industry companies traded in BIST is designed as applied quantitative research. Financial analysis, tradition financial statement analysis methods such as common-size percentage, ratio analysis, break-even analysis, trend analysis, fund flow analysis are commonly used (Gürbüz and Ergincan, 2004). However, to obtain more fruitful results, the fuzzy TOPSIS method is selected for the financial performance analysis of the defence industry companies in this study. TOPSis method is one of the multi-criteria decision-making models based on the concept that the selected alternative should have the shortest geometric distance from the positive ideal solution (Janko and Bernroider, 2005). In the fuzzy TOPSIS method, multiple alternatives against the selected criteria are evaluated. To analyse defence industry companies' financial performance with the fuzzy TOPSIS method, initially, the relevant companies are selected. In this context, three defence industry companies currently traded in BIST are included in this study. These companies are Aselsan Elektronik Sanayi ve Ticaret A.Ş (ASELS), Katmerciler Araç Üstü Ekipman Sanayi ve Ticaret A.Ş. (KATMR) and Otokar Otomotiv Savunma Sanayi A.Ş. (OTKAR). The other essential companies operating in the defence industry are not selected in this study because they have not gone public and so traded in BIST yet. Accordingly, this study's data set is obtained from financial ratios derived from balance sheets and income statements of these three defence industry companies traded in BIST. These companies' financial statements used to calculate financial ratios between 2010 and 2019 are taken from annual financial statements published on Borsa İstanbul and Public Disclosure Platform's official websites. In this study, to evaluate the liquidity of the defence companies, the current ratio and acid-test ratio are used as common liquidity ratios. To evaluate the indebtedness of the defence companies, leverage ratio, financing rate, short-term liabilities to total assets ratio and long term liabilities to total assets ratio are used in the study. To evaluate how well these companies are utilizing their assets and resources, the equity turnover rate accounts receivable turnover rate, and inventory turnover rate ratios are used as common efficiency ratios. Finally, net profit/equity rate, return on asset rate, gross profit on sales/net sales and operating income/ net sales ratio are calculated within the context of profitability ratios. After defence industry companies and financial ratios are selected, seven decision-makers, who have relevant academic studies before, are selected. Then, seven decision-makers are asked to evaluate and rate the financial ratios regarding defence industry companies' ten-year financial ratios. Then, depending on the responses of decision-makers, fuzzy decision matrixes are calculated.

\section{Findings And Discussion}

In this study, by doing applied research to measure the financial performance of defence industry companies traded in BIST, it is tried to explain the fuzzy TOPSIS method's processes. By the fuzzy TOPSIS method, the decision-making process becomes more accessible, uncertainty is removed, and better decisions are given. As a result of this study, by taking 13 criteria (financial ratios), a performance evaluation of three defence industry companies is made. With respect to fuzzy TOPSIS analysis result, Aselsan Elektronik Sanayi ve Ticaret A.Ş is the first, Otokar Otomotive Savunma Sanayi A.Ş. is the second and Katmerciler Araç Üstü Ekipman Sanayi ve Ticaret A.Ş is the last in terms of their financial performance. When the financial ratios of Aselsan are examined, it is seen that there has been a positive incremental increase during ten years. $90 \%$ of the sales of the company is carried out in domestic. This shows that Aselsan has an essential share in the domestic market and earns a significant income from sales in the domestic market. Additionally, when Aselsan is compared with the other two defence industry companies included in the study, the financial leverage ratio of Aselsan ranges between $40 \%$ and $50 \%$, the leverage ratios of the other two companies range between $70 \%$ and $80 \%$. The high financial leverage ratio, which shows the companies' indebtedness, is risky for companies. Hence, in terms of the leverage ratio, Aselsan seems better than the other two companies in terms of financial risk. Since the acid test ratio, short term liabilities, net profit/equity, return on assets ratios of Aselsan are better than the other two companies' ratios, Aselsan goes one step further among the other two companies. Simultaneously, because Aselsan shares some parts of its profits with shareholders and separates the other parts for new investments, Aselsan does not suffer from difficulties finding a financial resource. Depending on data derived from the companies' financial statements, it is seen that Aselsan has a healthier financial structure than the others. These findings are compatible with the results obtained with the fuzzy TOPSIS method.

\section{Conclusion, Recommendation And Limitation}

When the performance of these three companies in BIST is taken into consideration, it is seen that Otokar is the first, Aselsan is the second and Katmerciler is the last in terms of the share price. Although the study's findings demonstrate that Aselsan is a more valuable company in terms of financial criteria, investor evaluations in today's market conditions do not appear in that way. It is expected that the financial realities and value of the Aselsan will reflect on the stock exchange performance in the years ahead. From this perspective, the fuzzy TOPSIS method provides investors to opportunity to make a fundamental 
analysis. Accordingly, as well as its contributions to relevant literature, the study's findings will contribute to the practice by bringing a new perspective to stock investors. This perspective will lead to further studies, which will also contribute to the relevant literature. As well as seen in almost all applied research, this study has also some limitations. The first limitation is selecting a single industry to examine the financial performance with the fuzzy TOPSIS method. Another limitation of the study is the criteria that are selected based on 13 financial ratios. In further studies, new financial ratios may be employed as decisionmaking criteria to reach more fruitful conclusions. 


\section{Giriş}

Gelişmekte olan dünyada savunma sanayinin etkin bir yeri bulunmaktadır. Savunma sanayi, silahlı kuvvetlerinin ihtiyaç duyduğu savunma teçhizatlarını üretmenin yanı sıra ülkenin ekonomisinin büyümesine ve gelişmesine katkı sağlamaktadır. Birçok farklı sektörün, demir çelik, cam, otomotiv, elektrik ve elektronik gibi sektörlerin ürettiklerinden faydalanır ve bu sektörlerin gelişmesine de büyük bir katkı sağlamaktadır.

Cumhuriyetin kurulması ile Türkiye savunma sanayi sektörüne ayrıca önem vermeye başlamıştır. Ülkelerin dışarıdan ithal ettiği savunma teçhizatlarını azaltmak ve milli savunma sanayi şirketlerini geliştirmeye yönelik önemli projeler başlatılmıştır. Cumhuriyet dönemlerinde yerli savunma şirketleri Türk Silahlı Kuvvetlerinin (TSK) ihtiyaçlarının \%24'ünü karşılarken, yapılan çalışmalarla savunma sanayisindeki yerlilik oranının 2021 'de yüzde 71 'e, havacilık ve savunma sanayi ihracat gelirlerinin 6,2 milyar dolara, cirosunun 19,7 milyar dolara ve istihdamının 81,5 bine ulaşması hedeflenmektedir (Savunma Sanayi Dergilik, 2020).

Rekabetin sürekli arttığı dünyada şirketlerin devamlılı̆̆ için üretimde sürekliliği sağlayabilmesi ve kar elde edebilmesinde, finansal performansın ciddi bir rolü vardır. Finansal performans, şirketlerin ölçülebilir finansal verilerini kullanarak güçlü ve zayıf yönlerinin belirlenmesini kapsayan bir değerlendirmedir(Karcıoğlu v.d, 2020). İşletmeler finansal performanslarını genellikle mali tablolarından elde ettikleri oranlardan faydalanarak ölçmeye çalışmaktadırlar. Böylelikle finansal performans, işletmelerin geleceğe yönelik hedeflerine ne kadar ulaştığını ve zayıf olan yönlerinin ne kadarının düzeltildiğini gösteren geri bildirim aracı olarak kullanılmaktadır.

Yerel ve küresel piyasalarda rekabet edebilme bağlamında savunma sanayi şirketleri diğer sanayi dallarında faaliyet gösteren şirketlerde olduğu gibi, finansal performanslarına gereken önemi vermek zorundadır. Bu gerçekten hareketle bu çalışmada BİST'de işlem gören savunma sanayi şirketlerinin finansal performanslarını ölçülmesi amaçlanmaktadır. Çalışmada öncelikle benzer konularda yapılmış çalışmalar incelenmiştir. Bir sonraki bölümde Bulanık TOPSIS yöntemine ilişkin bilgi verilmiş, bu bölümü takiben söz konusu yöntemin BİST'te işlem gören savunma sanayi şirketlerin finansal performansını belirlemek amacıyla uygulaması anlatılmış ve son bölümde de elde edilen sonuçlar incelenmiştir. Çalışmanın bulgularının başta BIST'te işlem gören savunma sanayi şirketleri olmak üzere diğer tüm işletmelere finansal performans analizlerinde katkı sağlaması beklenmektedir.

\section{Literatür taraması}

Bu bölümde savunma sanayi ve finansal performans ile ilgili daha önce yapılan çalışmalar incelenmektedir. Daha önce yapılan çalışmaların bazıları aşağıda gösterilmektedir.

Değer (1986), çalışmasında savunma harcamalarının sosyal ve ekonomik etkilerinin araştırmıştır. Araştırma sonucu elde edilen bulgulara göre savunma harcamaları Ar-Ge yatırımları yolu ile ülkenin sahip olduğu güçlü bir ordunun sağladığı güven sosyal barışa katkı sağladığını tespit etmiştir.

Topçu (2010), çalışmasında savunma planlamalarının ekonomiye etkilerini ve savunma bütçelerini incelemiş ve bir bakış açısı geliştirmeye çalışmıştır. Sonuç olarak, savunma maliyetlerinin yüksek olduğunu ve ekonomiler üzerinde ciddi bir etkisi olduğu hatta çatışma yaşanan bölgelerde savunma maliyetlerinin daha da yüksek olduğu sonucuna ulaşmıştır.

Temiz (2012), çalışmasında Türk savunma sanayinin ekonomi üzerindeki etkilerini yıllara göre araştırmıştır. Araştırmada savunma sanayinin 1997-2009 yıllarındaki verilerden yararlanılmıştır. Sonuç olarak, Türk savunma sanayisinin ülke ekonomisine pozitif bir katkı sağladığını belirlemiştir.

Konukbay (2016), çalışmasında Ankara'da savunma sanayisinde faaliyet gösteren küçük, orta ve büyük işletmeler üzerinde uygulama ve model incelemesi yapmıştır. Sonuç olarak, yapılan yenilik eğitimlerinin arıttırılması, üniversite ve diğer kurumlar ile iş birliklerin geliştirilmesi, kamu desteklerinin arıttırılması gerektiğini belirtmiştir.

Demirhan ve Aracıoğlu (2017) çalışmalarında finansal performans ile İnovasyon arasındaki ilişkiye Borsa İstanbul teknoloji endeksinde işlem gören şirketler üzerinde TOPSIS yöntemi ile araştırma yapmışlardır. Sonuç olarak, TOPSIS skorları ile inovatif faaliyetler arasında istatiksel olarak anlamlı olmayan zayıf bir korelasyon olduğu sonucuna ulaşmışlardır.

Şişman (2017) çalışmasında küreselleşme, kriz ve savunma sanayini araştırmıştır. Araştırmasında SPRI verilerinden yararlanmıştır. Sonuç olarak, küresel dünyada savunma sanayinde Amerikan hegemonyasının kırılamadığını ve en büyük 10 savunma şirketinin 7 'sinin Amerikan şirketi olduğunu belirtmiştir. Kriz sonrası ülkelerin savunma sanayilerine yüksek miktarda harcama yaptıkları ve bu 
büyük boyutlu harcamalardan dolayı diğer alanlara yapılacak harcamaların payının azaldığı sonucuna ulaşmıştır.

Kayalı ve Aktaş (2018) yaptıkları çalışmada Borsa İstanbul'da işlem gören otomotiv şirketlerinin finansal performans analizini TOPSIS yöntemi ile araştırmışlardır. Sonuç olarak, araştırmaya dahil edilen 7 şirketin bazılarının grup içerisindeki sıralamasını istikrarlı bir şekilde korudukları ve bundan dolayı yatırımcılar tarafından aranan işletmeler oldukları belirlenmiştir.

Saygılı ve Şahin (2018) çalışmalarında hisse senedi yatırımcı kararı ve finansal performans arasındaki ilişkiyi Borsa İstanbul'da işlem gören çimento sektöründeki şirketler üzerinde incelemiş ve TOPSIS yöntemi ile analiz etmişlerdir. Sonuç olarak, çimento sektöründe işlem gören şirketlerin hisse senedi fiyatları ile finansal performansları arasında bir ilişki olmadığı tespitinde bulunulmuştur.

Bakır (2019) çalışmasında insansız hava araçlarının savunma sanayi harcamalarındaki yeri ve önemini incelemiştir. Sonuç olarak, savunma harcamalarında insansız hava araçları için her geçen gün ciddi kaynak ayrıldığını ve bu insansız hava araçlarını üreten şirketlerin Türkiye'yi bu teknolojide ithalatçı konumundan ihracatçı konumuna getirdiklerini belirtmiştir.

Bilici (2019) çalışmasında turizm sektörünün finansal performansını oran analizi ve TOPSIS yöntemi ile araştırmıştır. Sonuç olarak, 2001 ve 2008 global krizlerde başarılı kriz yönetiminin sektörün performansına olumlu yansıdığı sonucuna ulaşmıştır.

Özçelik ve Küçükçakal (2019) BİST'te işlem gören finansal kiralama ve faktöring şirketlerinin finansal performanslarını TOPSIS yöntemi ile analiz etmişlerdir. Çalışmanın sonucunda CRDFA şirketinin başarılı bir performans gösterdiği sonucu elde etmişlerdir.

Tezcan (2019) çalışmasında finansal performans ile ihracat düzeyi arasındaki ilişkiyi Türkiye otomotiv sanayisi üzerinde TOPSIS yöntemi ile araştırmıştır. Sonuç olarak, 2016 yllı için güçlü ve istatistiki olarak önemli bir ilişki bulunurken 2017 ve 2018 yılları için geçerli olmadığı sonucu elde etmiştir.

Yeşilyurt ve Yeşilyurt (2019) Türkiye'nin savunma sanayisin durumunu araştırmışlardır. Çalışmasında uluslararası kuruluşların yayınladıkları verilerden yararlanmıştır. Sonuç olarak, Türkiye savunma sanayisinin 1995 yılından ihracatında ve savunma harcamalarında artışlar olduğunu, diğer bir taraftan da ithalatta azaldığı sonucuna ulaşmışlardır.

Topal (2020) çalışmasında Türkiye'deki terör eylemleri ile savunma sanayi ilişkisini incelemiştir. Sonuç olarak, Türkiye'nin son 40 yılda yaşadığı terör olaylarında edinmiş olduğu askeri deneyimi ve başarısı savunma sanayisinde de gelişimi beraberinde getirmiş olduğunu ve savunma sanayindeki gelişimin ekonomik gelişime de katkı sağladığı tespitinde bulunmuştur.

\section{Veriler ve metodoloji}

$\mathrm{Bu}$ çalışmanın temel amacı Borsa İstanbul'da işlem gören savunma sanayi şirketlerinin finansal performanslarını analiz etmektir.

İşletmelerin finansal durumlarını ve bununla birlikte faaliyet sonuçlarının değerlendirilebilmesi, işletmenin amaçları ile uyumlu kararlar alınması için, yöneticiler ve yatırımcılar finansal performans analizlerine ihtiyaç duymaktadırlar. Finansal analizde, geleneksel mali tablolar analizi yöntemlerinden olan Dikey Yüzde Analizi, Oran Analizi, Kara Geçiş Analizi, Eğilim Yüzdeleri Analizi, Fon Akım Analizi vb., en yaygın kullanılan yöntemlerdir (Gürbüz ve Ergincan, 2004: 92). Daha sağlıklı sonuçlar almak için kullanılan Çok Amaçlı Karar Verme Yöntemlerinden olan AHP, TOPSIS, ELECTRE gibi matematiksel olan yöntemler de kullanılan diğer yöntemlerdir.

İşletmeler için finansal performansın iyi olmasının sağlayacağı faydalar şu şekilde sıralanabilir. (Ylldız, 2013: 47);

- Finansal performansın iyi olması uzun vadede bakış açısı geliştirmek için bir esneklik sağlamaktadır.

- Finansal performansın iyi olması işletmenin itibarını dolayısıyla kredibilitesini arttırmaktadır.

Sermaye piyasalarında, işletmelerin uygun koşullarda sermaye bulması ve uzun vadede faaliyetlerinde devam edebilmeleri için finansal performanslarının iyi bir düzeyde olması gerekmektedir.

Çalışmada savunma sanayi sektöründe faaliyet gösteren önemli sanayi şirketlerinin bazılarının daha halka açılmadıklarından dolayı mali tablolarına ulaşılamamıştır. Bu nedenden dolayı bu şirketler çalışmaya dahil edilememiştir. Bu da çalışmanın sınırlılığıdır. 
Bu çalışmanın veri setini Borsa İstanbul da faaliyet gösteren 3 savunma sanayi şirketlerinin bilanço ve gelir tablolarından yararlanarak elde edilen finansal oranlar oluşturmaktadır. Savunma sanayi şirketlerinin 2010-2019 dönemini kapsayan 10 yıllık süreçteki finansal oranların hesaplanmasında kullanılan finansal tablolar Borsa İstanbul ve Kamu Aydınlatma Platformunun (KAP) resmi internet sitelerinde yayınlanan yıllık finansal tablolardan sağlanmıştır. Çalışmanın verileri 2010-2019 yıllarını kapsadığı ve veri toplama zamanı 1 Ocak 2020 tarihinden önce olduğu için etik kurul izin belgesi düzenlenmemiştir.

2010-2019 yılları arasında analiz kapsamında incelenecek işletmeler ve kullanılacak Borsa İstanbul (BİST) işlem kodları aşă̆ıdaki tabloda gösterilmiştir.

Tablo 1: Şirketlerin ismi ve Borsa Kodları

\begin{tabular}{|c|c|}
\hline BİST İşlem Kodu & İŞLETME ADI \\
\hline ASELS & ASELSAN ELEKTRONİK SANAYİ VE TICARET A.Ş. \\
\hline KATMR & KATMERCİLER ARAÇ ÜSTÜ EKİPMAN SANAYİ VE \\
& TİCARET A.Ş. \\
\hline OTKAR & OTOKAR OTOMOTIV SAVUNMA SANAYİ A.Ş. \\
\hline
\end{tabular}

Çalışmada kullanılacak finansal oranlar ise Tablo 2' de verilmiştir.

Tablo 2: Çalışmada Kullanılacak Finansal Oranlar

\begin{tabular}{|c|c|c|}
\hline \multirow[b]{3}{*}{ LİKİDİTE ORANLARI } & Kullanılan Oranlar & Sembolü \\
\hline & Cari Oran & $\mathrm{CO}$ \\
\hline & Asit-Test Oran1 & $\mathrm{AT}$ \\
\hline \multirow[b]{4}{*}{ BORÇLULUK ORANLARI } & Kaldıraç Oranı & $\mathrm{KO}$ \\
\hline & Finansman Oranı & FO \\
\hline & $\begin{array}{l}\text { Kısa Vadeli Yabancı Kaynaklar/ } \\
\text { Toplam varlıklar Oranı }\end{array}$ & KVYK/TV \\
\hline & $\begin{array}{l}\text { Uzun Vadeli Yabancı Kaynaklar/ } \\
\text { Toplam Varlıklar Oranı }\end{array}$ & UVYK/TV \\
\hline \multirow[b]{3}{*}{$\begin{array}{l}\text { FAALIYET (ETKİNLİK) } \\
\text { ORANLARI }\end{array}$} & Öz kaynak Devir Hizı & ÖDH \\
\hline & Alacak Devir H1zı & $\mathrm{ADH}$ \\
\hline & Stok Devir Hiz1 & $\mathrm{SDH}$ \\
\hline \multirow[b]{4}{*}{ KARLILIK ORANLARI } & Net Kar/Özsermaye Oranı & NK/ÖS \\
\hline & Aktif Karlılık Oranı & AK \\
\hline & Brüt Satış Karı/Net Satışlar Oranı & BSK/NS \\
\hline & Faaliyet Karı/Net Satışlar Oranı & FK/NS \\
\hline
\end{tabular}

\section{Bulanık TOPSİS yöntemi}

TOPSIS çok Kriterli Karar Verme (ÇKKV) yöntemlerinden bir tanesidir. Bu yöntem ilk olarak 1981 yılında Hwang ve Yoon tarafından geliştirilmiştir (Ecer 2007). TOPSIS yönteminde ideal çözüm için lazım olan yakınlık bulunurken, pozitif ideal çözüme uzaklık ile beraber negatif ideal çözüme uzaklıklar birlikte değerlendirilmektedir. Pozitif ve negatif uzaklıkların karşılaştırılması sonrası tercih sıralaması işlemleri yapılmaktadır (Janko ve Bernroider, 2005). 
En ideal değerlendirmeleri yapmak, ağırlıkları oluşturmak hem de en uygun sonuca ulaşmak için çok kriterli Fuzzy karar verme yöntemine ihtiyaç duyulmaktadır (Chen, 2001: 66). TOPSIS yönteminde bulanık değerlerden yararlanarak yapılan çalışmaların başında Negi (1989) doktora tezi teziyle, Chen ve Hwang (1992) ise yayımladıkları bir kitapla yöntemi kullanmaya başlamışlardır. Yöntemi başlatanlar Negi ve Chen ile Hwang olsalar da Bulanık TOPSIS algoritmasını sonuçlandıran kişi 2000 yılında yazdığı makale ile Chen sonuçlandırmıştır (Ecer, 2006).

Bir üçgen sayısı " $\mathrm{n}$ " $\left(n_{1}, n_{2}, n_{3}\right)$ şeklinde gösterilmekle birlikte $\mu_{n}(x)$ üyelik fonksiyonu Şekil 1' deki gibi gösterilmektedir (Chen, 2001: 3).

$\mu_{n}(x)=\left\{\begin{array}{c}0, x<n_{1} \\ \frac{x-n_{1}}{n_{2}-n_{1}}, n_{1} \leq x \leq n_{2} \\ \frac{x-n_{g}}{n_{2}-n_{g}}, n_{2} \leq x \leq n_{3} \\ 0, x>n_{3}\end{array}\right.$

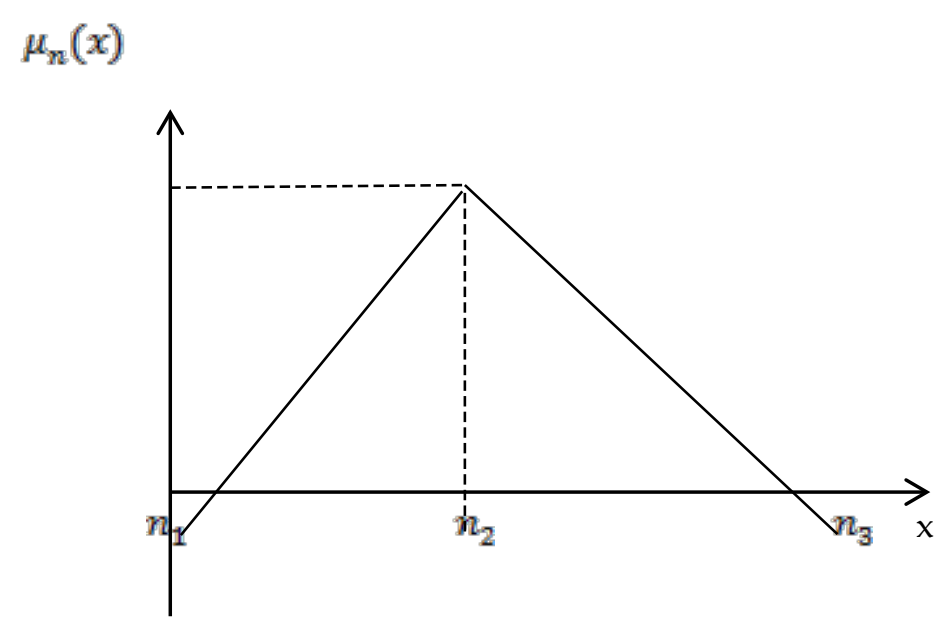

Şekil 1. N Üçgen Fuzzy Sayısı

$m=\left(m_{1}, m_{2}, m_{3}\right)$ ve $n=\left(n_{1}, n_{2}, n_{3}\right)$ bu iki üçgen Bulanık sayısını göstermektedir. Bunların arasındaki uzaklığı belirlemek ya da başka bir ifade ile hesaplamak için Vertex Yöntemine ihtiyaç duyulmaktadır. İki üçgen üçgen Bulanık sayısının aralarındaki uzaklığı belirlemede kullanılan Vertex yöntemi şöyle formüle edilmektedir (Chen, 2001).

$\mathrm{d}(\mathrm{m}, \mathrm{n})=\sqrt{\frac{1}{3}\left[\left(m_{1}-n_{1}\right)^{2}+\left(m_{2}-n_{2}\right)^{2}+\left(m_{3}-n_{3}\right)^{2}\right]}$

Dilsel değişken, değişkenin değeri olarak dilde kullanılan cümleler dilsel değişkendirler (Zadeh, 1987). Örnek olarak güzellik bir dilsel değişkeni ifade etmektedir. Çünkü değerleri çok çirkin, çirkin, orta, güzel, çok güzel şeklinde değerleri alabilmektedirler. Dilsel değişken Bulanık sayıları ile gösterilebilmektedir (Dündar, Ecer, Özdemir, 2007: 293).

Bulanık TOPSIS yönteminde nitel ve nicel ölçütleri anlamlı bir biçimde değerlendirilebilmektedir. Bulanık TOPSIS metodu çok esnek bir yapısı vardır (Ecer, 2007). Bulanık TOPSIS metodu verilen kararların farklılık gösterdiği zamanlarda grup karar vermeyi gerektiren problemler için ideal bir yöntemdir. Ölçeklerin ağırlıkları ve ölçeklerin önem dereceleri dilsel değişkenler olarak düşünülmektedir. Dilsel değişkenlerden ölçeklerin yanı sıra kriterlerin diğer kriterlere göre alternatiflerinin önem derecelerini ve kriterin önemini belirlemek için faydalanılmaktadır. Bu dilsel değişkenler pozitif üçgen sayısı olarak Tablo 3 ve 4 'deki gibi ifade edilmektedir (Chen, 2000: 4-5). 
Tablo 3: Her Bir Kriterin Önem Ağırlığı için Dilsel Değişkenler

\begin{tabular}{|l|l|l|l|l|}
\hline Çok Düşük & ÇD & 0,0 & 0,0 & 0,1 \\
\hline Düşük & D & 0,0 & 0,1 & 0,3 \\
\hline Orta Düşük & OD & 0,1 & 0,3 & 0,5 \\
\hline Orta & O & 0,3 & 0,5 & 0,7 \\
\hline Orta Yüksek & OY & 0,5 & 0,7 & 0,9 \\
\hline Yüksek & Y & 0,7 & 0,9 & 1,0 \\
\hline Çok Yüksek & ÇY & 0,9 & 1,0 & 1,0 \\
\hline
\end{tabular}

Tablo 4: Kriter Önem Dereceleri için Dilsel Değişkenler

\begin{tabular}{|l|l|l|l|l|}
\hline Çok Kötü & ÇK & 0 & 0 & 1 \\
\hline Kötü & K & 0 & 1 & 3 \\
\hline Orta Kötü & OK & 1 & 3 & 5 \\
\hline Orta & O & 3 & 5 & 7 \\
\hline Orta İyi & Oİ & 5 & 7 & 9 \\
\hline İyi & İ & 7 & 9 & 10 \\
\hline Çok İyi & Ç் & 9 & 10 & 10 \\
\hline
\end{tabular}

a karar vericiden oluşan $x_{i j}^{a}$ ve $w_{j}^{a}$ 'nin a'nıncı karar vericinin önem derecesi ve kriter ağırlığını gösterdiği bir grupta her bir kritere göre alternatiflerinin kriter değeri ve ağırlığı aşağıda gösterildiği şekilde hesaplanmaktadır.

$x_{i j}=\frac{1}{a}\left[x_{i j}^{1}(+) x_{i j}^{2}(+) \ldots(+) x_{i j}^{a}\right]$

$w_{j}=\frac{1}{a}\left[w_{j}^{1}(+) w_{j}^{2}(+) \ldots(+) w_{j}^{a}\right]$

Bulanık karar verme matrisi aşağıdaki gibi formüle edilmektedir.

$$
\begin{aligned}
& \begin{array}{lllll}
C_{1} & C_{2} & \ldots & C_{n}
\end{array} \\
& D=\stackrel{A_{1}}{A_{n}} \underset{:}{\stackrel{A_{m}}{A_{m 1}}}\left[\begin{array}{cccc}
x_{11} & x_{12} & \ldots & x_{1 n} \\
x_{21} & x_{22} & \ldots & x_{2 n} \\
x_{m 1} & x_{m 2} & \ldots & x_{m n}
\end{array}\right], \quad W=\left[\begin{array}{lll}
w_{1} & w_{2} \ldots & w_{n}
\end{array}\right]
\end{aligned}
$$

Burada $x_{i j}(\forall i, j)$ ve $w_{j} j=(1,2, \ldots, n)$ dilsel değişkendir. Bu şekilde yazılan dilsel değişkenler üçgen Bulanık sayılar $x_{i j}=\left(a_{i j}, b_{i j}, c_{i j}\right)$ ve $w_{j}=\left(w_{j 1}, w_{j 2}, w_{j 3}\right)$ şeklinde tanımlanmaktadır.

Normalize edilmiş Bulanık Karar matrisi R ile gösterilmektedir ve

$R=\left(r_{i j}\right)_{\operatorname{mxn}}$

Bu şekilde ifade edilmektedir. Burada B fayda kriterleri kümesi olup aşağıdaki gibi hesaplanmaktadır.

$r=\left(\frac{a_{i j}}{c_{j}}, \frac{b_{i j}}{c_{j j}}, \frac{c_{i j}}{c_{j j}}\right), J \in B$

$c_{j}^{*}=m_{i} a x c_{i j}$ eğer $J \in B$ ise 
Yukarıda yazılan normalleştirme yöntemi, normalize edilmiş üçgen Bulanık sayılarının $(0,1)$ aralığında olmasını sağlamaktadır.

Kriterlerin önem düzeyleri ve farklı ağırlıkları dikkate alınarak ağırlıklı normalleştirilmiş Bulanık karar matrisi aşağıdaki gibi yazılmaktadır.

$V=\left(v_{i j}\right)_{m x n} \quad i=1,2, \ldots, n$

Yukarıdaki matrisin öğeleri ise,

$v_{i j}=r_{i j}(.) w_{j}$

Formülünün yardımı ile hesaplanmaktadır.

Ağırlığı normalize edilen Bulanık karar matrisine göre $\forall i, j i c ̧ i n v_{i j}$ elemanları normalize edilmiş pozitif üçgen Bulanık sayılarıdır ve $(0,1)$ aralığında bulunmaktadırlar.

Bulanık pozitif ideal çözüm $A^{*}$ ve Bulanık negatif ideal çözüm $A^{-}$oluşturulmak üzere;

$A^{*}=\left(v_{1}^{*}, v_{2}^{*}, \ldots, v_{n}^{*}\right)$

$A^{-}=\left(v_{1}^{-}, v_{2}^{-}, \ldots, v_{n}^{-}\right)$

Yukarıdaki gibi tanımlanmaktadır. Burada $v_{j}^{*}=(1,1,1)$ ve $v_{j}^{-}=(0,0,0)^{\prime}$ dır.

Her bir alternatifin $A^{*}$ ve $A^{-`}$ den uzaklığı sırasıyla aşağıdaki gibidir;

$d_{i}^{*}=\sum_{j}^{n}=1 d\left(v_{i j}, v_{j}^{*}\right), \quad i=1,2, \ldots, m$

$d_{j}^{-}=\sum_{j}^{n}=1 d\left(v_{i j}, v_{j}^{-}\right), \quad i=1,2, \ldots, m$

İle hesaplanmaktadır. Burada d (i) Bulanık sayıları arasındaki uzaklığı göstermektedir.

Yakınlık katsayısı ile tüm alternatiflerin derecelerine göre sıralama yapılmakla birlikte, derece puanlamasını aşağıdaki gibi hesaplanmaktadır.

$C C_{i}=\frac{d_{j}^{-}}{d_{i}^{*}+d_{i}^{-}} \quad i=1,2, \ldots, m$

İle hesaplanmaktadır.

Bulanık TOPSIS algoritması aşağıdaki gibi özetlenebilir;

1. Adım: Karar vericilerin değerlendirme kriterlerinin belirlenmesi.

2. Adım: Karar vericilerin alternatif dilsel değişkenlerinin değerlendirilmesi.

3. Adım: Bulanık karar matrisinin oluşturulması.

4. Adım: Normalize Bulanık karar matrisinin oluşturulması.

5. Adım: Ağırlıklandırılmış Normalize Bulanık karar matrisinin oluşturulması.

6. Adım: Pozitif İdeal Çözümün FPİÇ $(1,1$,$) hesaplanması$

7. Adım: Negatif İdeal Çözümün FNİÇ $(0,0,0)$ hesaplanması.

8. Adım: Alternatiflerin FPIÇ ve FNIÇ'ten uzaklıklarının hesaplanması.

9. Adım: Alternatiflerin yakınlık katsayısının hesaplanması.

10.Adım: Yakınlık katsayılarına göre sıralamanın yapılması.

\section{Borsa İstanbul'da işlem gören savunma sanayi şirketlerinin bulanık TOPSIS yöntemi yardımı ile değerlendirilmesi}

Çalışmanın bu bölümünde borsada işlem gören savunma sanayi şirketleri Bulanık TOPSIS yöntemi kullanılarak değerlendirilecektir. Bu amaçla BISTT'de işlem gören üç savunma sanayi şirketi, ASELSAN ELEKTRONIK SANAYİ VE TİCARET A.Ş., KATMERCILER ARAÇ ÜSTÜ EKIPMAN SANAYI VE TICARET A.Ş. ve OTAKAR OTOMOTIV SAVUNMA SANAYİ A.Ş belirlenmiş ve sırasıyla (A1), (A2) ve (A3) olarak gösterilmiştir. Daha sonra finans alanında çalışmalar yapan yedi karar verici (KV1, KV2, KV3, KV4, KV5, KV6, KV7) belirlenmiştir.

Daha önce yapılan benzer çalışmalardan da yararlanılarak 13 tane oran değerlendirme kriteri olarak kullanılmıştır. Kullanılan oranlar; C 1, C 2, C 3, ... C 13 şeklinde gösterilmiştir. Çalışmada kullanılan 
oranların önem derecelerine göre değerlendirilmesi A0 olarak ifade edilmiştir.

Adım 1: Karar vericilerin Değerlendirme Kriterlerinin Belirlenmesi

Tablo 5: 2010-2019 yılları için Karar Vericilere Ait Oranlara göre Dilsel Değerlendirmeler

\begin{tabular}{|c|c|c|c|c|c|c|c|c|c|}
\hline & & \multicolumn{2}{|c|}{ İŞLETMELER } & \multicolumn{6}{|c|}{$\begin{array}{l}\text { KARAR VERICII UZMANLAR VE } \\
\text { DEĞERLENDIRMELERİ }\end{array}$} \\
\hline \multirow{5}{*}{ 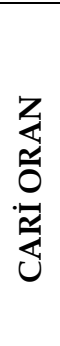 } & \multirow{5}{*}{ ü } & & KV1 & KV2 & KV3 & KV4 & KV5 & KV6 & KV7 \\
\hline & & A0 & OY & $\mathrm{O}$ & ÇY & $\mathbf{Y}$ & OD & $\mathrm{O}$ & $\mathbf{Y}$ \\
\hline & & A1 & Ç் & Çİ & Çİ & Çі் & $\dot{\mathrm{I}}$ & Çì & $\dot{\mathrm{I}}$ \\
\hline & & A2 & OK & OK & OK & Oİ & $\mathrm{O}$ & $\mathrm{O}$ & $\mathrm{O}$ \\
\hline & & A3 & $\mathrm{K}$ & $\mathrm{K}$ & $\mathrm{K}$ & $\mathrm{O}$ & $\mathrm{O}$ & $\mathrm{O}$ & OK \\
\hline \multirow{5}{*}{ 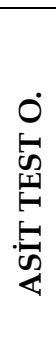 } & \multirow{5}{*}{ U } & & KV1 & KV2 & KV3 & KV4 & KV5 & KV6 & KV7 \\
\hline & & A0 & $\mathrm{Y}$ & $\mathrm{O}$ & ÇY & ÇY & $\mathrm{O}$ & $\mathrm{O}$ & $\mathrm{Y}$ \\
\hline & & $\overline{\mathrm{A} 1}$ & Çً̇ & Ç்ً & $\dot{\mathbf{I}}$ & Çİ & Oİ & Çً̇ & $\dot{\mathbf{I}}$ \\
\hline & & A2 & K & OK & OK & K & $\mathbf{O}$ & $\mathrm{O}$ & $\mathrm{O}$ \\
\hline & & A3 & K & $\mathrm{K}$ & OK & OK & Oİ & $\mathrm{O}$ & OK \\
\hline \multirow{5}{*}{ 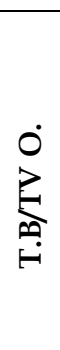 } & \multirow{5}{*}{ u } & & KV1 & KV2 & KV3 & KV4 & KV5 & KV6 & KV7 \\
\hline & & A0 & $\mathrm{Y}$ & OY & ÇY & $Y$ & OY & $Y$ & $Y$ \\
\hline & & A1 & $\dot{\mathbf{I}}$ & Oİ & $\dot{\mathbf{I}}$ & Çі் & $\mathrm{O}$ & $\mathrm{O}$ & Oİ \\
\hline & & A2 & $\mathbf{O}$ & $\mathrm{K}$ & OK & OK & $\mathrm{O}$ & Oİ & $\mathrm{O}$ \\
\hline & & A3 & OK & K & $\mathbf{K}$ & $\mathrm{O}$ & $\mathrm{O}$ & Oİ & $\mathrm{O}$ \\
\hline \multirow{5}{*}{\begin{tabular}{l}
0 \\
0 \\
\multirow{2}{*}{} \\
$\stackrel{0}{0}$ \\
0
\end{tabular}} & \multirow{5}{*}{ ü } & & KV1 & KV2 & KV3 & KV4 & KV5 & KV6 & KV7 \\
\hline & & A0 & ÇY & OY & ÇY & $\mathbf{Y}$ & OY & $\mathrm{Y}$ & $\mathrm{Y}$ \\
\hline & & A1 & $\dot{\mathrm{I}}$ & Oİ & $\dot{\mathbf{I}}$ & $\dot{\mathbf{I}}$ & $\dot{\mathbf{I}}$ & $\mathbf{K}$ & Oİ \\
\hline & & A2 & OK & $\mathrm{K}$ & OK & O & $\mathrm{O}$ & $\dot{\mathbf{I}}$ & $\mathbf{O}$ \\
\hline & & A3 & ÇK & K & K & $\mathrm{O}$ & $\mathrm{O}$ & $\dot{\mathrm{I}}$ & $\mathrm{O}$ \\
\hline
\end{tabular}


Tablo 5: (Devam) 2010-2019 yılları için Karar Vericilere Ait Oranlara göre Dilsel Değerlendirmeler

\begin{tabular}{|c|c|c|c|c|c|c|c|c|c|c|}
\hline & & \multicolumn{3}{|c|}{ İŞLETMELER } & \multicolumn{6}{|c|}{$\begin{array}{l}\text { KARAR VERICII UZMANLAR VE } \\
\text { DEĞERLENDIRMELERİ }\end{array}$} \\
\hline \multirow{5}{*}{$\frac{z}{\Sigma}$} & \multirow{5}{*}{ un } & & & KV1 & KV2 & KV3 & KV4 & KV5 & KV6 & KV7 \\
\hline & & \multicolumn{2}{|c|}{ A0 } & $\mathbf{Y}$ & OY & $\mathbf{O}$ & ÇY & OY & OY & $\mathbf{O}$ \\
\hline & & \multicolumn{2}{|c|}{ A1 } & $\dot{\mathrm{I}}$ & $\dot{\mathrm{I}}$ & Çi் & Çi் & Oİ & $\dot{\mathrm{I}}$ & $\mathbf{O}$ \\
\hline & & \multicolumn{2}{|c|}{ A2 } & OK & $\mathbf{K}$ & OK & $\mathbf{K}$ & $\mathbf{O}$ & OK & $\mathbf{K}$ \\
\hline & & \multicolumn{2}{|c|}{ A3 } & OK & $\mathbf{K}$ & OK & ÇK & OK & OK & $\mathbf{O}$ \\
\hline \multirow{5}{*}{$\frac{z}{5}$} & \multirow{5}{*}{ u } & & & KV1 & KV2 & KV3 & KV4 & KV5 & KV6 & KV7 \\
\hline & & \multicolumn{2}{|c|}{ A0 } & OY & $\mathbf{Y}$ & $\mathrm{O}$ & $\mathbf{Y}$ & OY & ÇY & $\mathbf{O}$ \\
\hline & & \multicolumn{2}{|c|}{$\overline{\mathrm{A1}}$} & Oİ & $\mathrm{O}$ & $\dot{\mathrm{I}}$ & Çí & Oİ & Oİ & Oİ \\
\hline & & \multicolumn{2}{|c|}{ A2 } & OK & OK & OK & Oİ & $\mathbf{O}$ & $\mathbf{O}$ & $\mathrm{K}$ \\
\hline & & \multicolumn{2}{|c|}{ A3 } & $\mathbf{O}$ & $\mathrm{O}$ & $\mathrm{O}$ & OK & $\mathbf{O}$ & Oİ & $\mathrm{O}$ \\
\hline \multirow{5}{*}{ 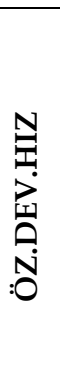 } & \multirow{5}{*}{$\hat{0}$} & & KV1 & KV2 & KV3 & KV4 & KV5 & KV6 & \multicolumn{2}{|c|}{ KV7 } \\
\hline & & A0 & ÇY & OD & $\mathrm{O}$ & OD & $\mathrm{O}$ & $\mathbf{Y}$ & \multicolumn{2}{|c|}{ OY } \\
\hline & & A1 & $\mathrm{K}$ & Oİ & $\mathrm{O}$ & Çi் & OK & K & \multicolumn{2}{|c|}{ OK } \\
\hline & & A2 & Oİ & $\mathrm{K}$ & Oİ & Oİ & Oİ & $\dot{\mathbf{I}}$ & \multicolumn{2}{|c|}{ Oİ } \\
\hline & & A3 & $\dot{\mathbf{I}}$ & K & Oİ & K & Oİ & Çi் & \multicolumn{2}{|c|}{ Oİ } \\
\hline \multirow{5}{*}{ 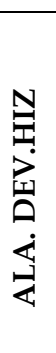 } & \multirow{5}{*}{$u^{\infty}$} & & & KV1 & KV2 & KV3 & KV4 & KV5 & KV6 & KV7 \\
\hline & & $\overline{\mathrm{A} 0}$ & & $\mathrm{O}$ & OY & ÇY & $\mathbf{O}$ & $\mathbf{Y}$ & $\mathbf{Y}$ & $\bar{Y}$ \\
\hline & & A1 & & $\mathrm{O}$ & OK & OK & $\dot{I}$ & $\mathbf{O}$ & $\mathbf{O}$ & OK \\
\hline & & A2 & & OK & $\mathrm{O}$ & $\mathbf{O}$ & $\mathbf{O}$ & $\mathbf{O}$ & $\mathbf{O}$ & OK \\
\hline & & $\overline{\mathrm{A} 3}$ & & $\dot{\mathbf{I}}$ & Oİ & $\mathbf{O}$ & $\dot{\mathbf{I}}$ & Oİ & Oİ & $\dot{\mathbf{I}}$ \\
\hline \multirow{5}{*}{ فำ } & \multirow{5}{*}{ u } & & & KV1 & KV2 & KV3 & KV4 & KV5 & KV6 & KV7 \\
\hline & & $\mathrm{A0}$ & & $\overline{\text { OY }}$ & OY & ÇY & $\bar{D}$ & $\mathbf{Y}$ & OY & $\mathrm{Y}$ \\
\hline & & A1 & & $\mathbf{O}$ & $\mathrm{O}$ & $\mathrm{O}$ & Çİ & $\dot{\mathbf{I}}$ & $\dot{\mathbf{I}}$ & $\dot{\mathbf{I}}$ \\
\hline & & $\overline{\mathrm{A} 2}$ & & ÇK & OK & OK & OK & OK & $\mathbf{O}$ & OK \\
\hline & & $\mathbf{A 3}$ & & Ç̇ं & $\dot{\mathbf{I}}$ & Oİ & $\dot{\mathbf{I}}$ & $\dot{\mathbf{I}}$ & $\dot{\mathbf{I}}$ & $\dot{\mathrm{I}}$ \\
\hline
\end{tabular}


Tablo 5: (Devam) 2010-2019 yılları için Karar Vericilere Ait Oranlara göre Dilsel Değerlendirmeler

\begin{tabular}{|c|c|c|c|c|c|c|c|c|c|}
\hline & & İŞLI & IELER & & AR V & RİCं & $\overline{\mathrm{ZMAI}}$ & LAR & TLARI \\
\hline \multirow{5}{*}{ 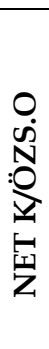 } & \multirow{5}{*}{ 르 } & & KV1 & KV2 & KV3 & KV4 & KV5 & KV6 & KV7 \\
\hline & & A0 & ÇY & $Y$ & $Y$ & D & ÇY & ÇY & OY \\
\hline & & $\overline{\text { A1 }}$ & Oİ & OK & $\mathrm{O}$ & Çं & $\dot{\mathbf{I}}$ & $\mathbf{O}$ & Oİ \\
\hline & & A2 & ÇK & $\mathrm{K}$ & $\mathrm{K}$ & ÇK & $\mathrm{K}$ & $\mathrm{K}$ & $\mathrm{O}$ \\
\hline & & A3 & ÇI & $\dot{\mathrm{I}}$ & $\mathrm{O}$ & Çí & $\dot{\mathrm{I}}$ & $\dot{\mathbf{I}}$ & $\dot{\mathrm{I}}$ \\
\hline \multirow{5}{*}{ 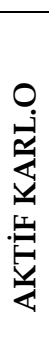 } & \multirow{5}{*}{$\bar{u}$} & & KV1 & KV2 & KV3 & KV4 & KV5 & KV6 & KV7 \\
\hline & & A0 & ÇY & $\mathbf{Y}$ & OY & OD & ÇY & ÇY & OY \\
\hline & & A1 & Oİ & Oİ & $\mathrm{O}$ & Çі் & $\dot{\mathbf{I}}$ & $\dot{\mathbf{I}}$ & $\dot{\mathbf{I}}$ \\
\hline & & A2 & ÇK & OK & K & K & OK & K & OK \\
\hline & & A3 & $\mathrm{O}$ & $\mathrm{O}$ & OK & $\dot{\mathbf{I}}$ & OI & Oİ & Oİ \\
\hline \multirow{5}{*}{ 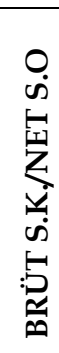 } & \multirow{5}{*}{$\tilde{u}$} & & KV1 & KV2 & KV3 & KV4 & KV5 & KV6 & KV7 \\
\hline & & A0 & ÇY & $\mathrm{O}$ & $\mathrm{O}$ & D & OY & ÇY & $Y$ \\
\hline & & $\overline{\text { A1 }}$ & $\mathrm{O}$ & $\mathrm{O}$ & $\mathrm{O}$ & Ç亡 & Oİ & $\mathrm{O}$ & Oİ \\
\hline & & A2 & $\mathrm{O}$ & Oİ & OK & $\dot{\mathbf{I}}$ & $\mathrm{O}$ & $\dot{\mathbf{I}}$ & $\mathbf{O}$ \\
\hline & & A3 & OK & $\mathrm{O}$ & OK & Oİ & $\mathrm{O}$ & $\mathrm{O}$ & $\mathrm{O}$ \\
\hline & & & & & & & & & \\
\hline \multirow{5}{*}{ 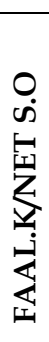 } & \multirow{5}{*}{$\stackrel{m}{u}$} & & KV1 & KV2 & KV3 & KV4 & KV5 & KV6 & KV7 \\
\hline & & A0 & $\mathbf{Y}$ & ÇY & ÇY & D & $\mathbf{Y}$ & ÇY & OY \\
\hline & & A1 & $\dot{\mathrm{I}}$ & Oİ & $\mathrm{O}$ & Ç亡 & $\dot{\mathbf{I}}$ & $\dot{\mathbf{I}}$ & Oİ \\
\hline & & A2 & $\dot{\mathbf{I}}$ & Oİ & OK & $\dot{\mathbf{I}}$ & $\mathrm{O}$ & Oİ & Oİ \\
\hline & & A3 & K & OK & $\mathrm{K}$ & $\dot{\mathrm{I}}$ & $\mathrm{O}$ & $\mathrm{O}$ & $\mathrm{O}$ \\
\hline
\end{tabular}


Adım 2: Karar Vericilerin Alternatif Dilsel Değişkenlerinin Değerlendirilmesi

Tablo 6: Karar Vericilerin Değerlendirmelerinin Sayı Karşılıkları

\begin{tabular}{|c|c|c|c|c|c|c|c|c|c|c|c|c|c|c|c|c|c|c|c|c|c|c|}
\hline & İŞLETMELER & \multicolumn{21}{|c|}{ KARAR VERICİ UZMANLAR VE NOTLARI } \\
\hline KRİTERELER & & \multicolumn{3}{|c|}{ KV1 } & \multicolumn{3}{|c|}{ KV2 } & \multicolumn{3}{|c|}{ KV3 } & \multicolumn{3}{|c|}{ KV4 } & \multicolumn{3}{|c|}{ KV5 } & \multicolumn{3}{|c|}{ KV6 } & \multicolumn{3}{|c|}{ KV7 } \\
\hline \multirow{5}{*}{ 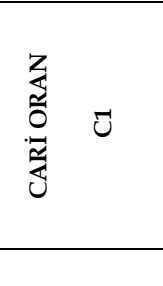 } & A0 & 0,50 & 0,70 & 0,90 & 0,30 & 0,50 & 0,70 & 0,90 & 1,00 & 1,00 & 0,70 & 0,90 & 1,00 & 0,10 & 0,30 & 0,50 & 0,30 & 0,50 & 0,70 & 0,70 & 0,90 & 1,00 \\
\hline & A1 & 9,00 & 10,00 & 10,00 & 9,00 & 10,0 & 10,00 & 9,00 & 10,0 & 10,00 & 9,00 & 10,00 & 10,00 & 7,00 & 9,00 & 10,00 & 9,00 & 10,00 & 10,00 & 7,00 & 9,00 & 10,00 \\
\hline & A2 & 1,00 & 3,00 & 5,00 & 1,00 & 3,00 & 5,00 & 1,00 & 3,00 & 5,00 & 5,00 & 7,00 & 9,00 & 3,00 & 5,00 & 7,00 & 3,00 & 5,00 & 7,00 & 3,00 & 5,00 & 7,00 \\
\hline & A3 & 0,00 & 1,00 & 3,00 & 1,00 & 3,00 & 5,00 & 0,00 & 1,00 & 3,00 & 3,00 & 5,00 & 7,00 & 3,00 & 5,00 & 7,00 & 3,00 & 5,00 & 7,00 & 1,00 & 3,00 & 5,00 \\
\hline & İŞLETMELER & \multicolumn{21}{|c|}{ KARAR VERICİ UZMANLAR VE NOTLARI } \\
\hline KRİTERELER & & \multicolumn{3}{|c|}{ KV1 } & \multicolumn{3}{|c|}{ KV2 } & \multicolumn{3}{|c|}{ KV3 } & \multicolumn{3}{|c|}{ KV4 } & \multicolumn{3}{|c|}{ KV5 } & \multicolumn{3}{|c|}{ KV6 } & \multicolumn{3}{|c|}{ KV7 } \\
\hline \multirow{5}{*}{ 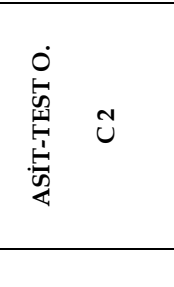 } & A0 & 0,70 & 0,90 & 1,00 & 0,30 & 0,50 & 0,70 & 0,90 & 1,0 & 1,00 & 0,90 & 1,00 & 1,00 & 0,30 & 0,50 & 0,70 & 0,30 & 0,50 & 0,70 & 0,70 & 0,90 & 1,00 \\
\hline & A1 & 9,00 & 10,00 & 10,00 & 9,00 & 10,0 & 10,00 & 7,00 & 9,00 & 10,00 & 9,00 & 10,00 & 10,00 & 5,00 & 7,00 & 9,00 & 9,00 & 10,00 & 10,00 & 7,00 & 9,00 & 10,00 \\
\hline & A2 & 0,00 & 1,00 & 3,00 & 1,00 & 3,00 & 5,00 & 1,00 & 3,00 & 5,00 & 0,00 & 1,00 & 3,00 & 3,00 & 5,00 & 7,00 & 3,00 & 5,00 & 7,00 & 3,00 & 5,00 & 7,00 \\
\hline & A3 & 0,00 & 1,00 & 3,00 & 0,00 & 1,00 & 3,00 & 1,00 & 3,00 & 5,00 & 1,00 & 3,00 & 5,00 & 5,00 & 7,00 & 9,00 & 3,00 & 5,00 & 7,00 & 1,00 & 3,00 & 5,00 \\
\hline & IŞLETMELER & \multicolumn{21}{|c|}{ KARAR VERİCI UZMANLAR VE NOTLARI } \\
\hline KRİTERELER & & & KV & & & $\mathrm{KV}$ & & & KV & & & $\mathrm{KV}$ & & & KV5 & & & KV6 & & & KV7 & \\
\hline & A0 & 0,70 & 0,90 & 1,00 & 0,50 & 0,70 & 0,90 & 0,90 & 1,0 & 1,00 & 0,70 & 0,90 & 1,00 & 0,50 & 0,70 & 0,90 & 0,70 & 0,90 & 1,00 & 0,70 & 0,90 & 1,00 \\
\hline 0 & A1 & 7,00 & 9,00 & 10,00 & 5,00 & 7,00 & 9,00 & 7,00 & 9,00 & 10,00 & 9,00 & 10,00 & 10,00 & 3,00 & 5,00 & 7,00 & 3,00 & 5,00 & 7,00 & 5,00 & 7,00 & 9,00 \\
\hline 5 & A2 & 3,00 & 5,00 & 7,00 & 0,00 & 1,00 & 3,00 & 1,00 & 3,00 & 5,00 & 1,00 & 3,00 & 5,00 & 3,00 & 5,00 & 7,00 & 5,00 & 7,00 & 9,00 & 3,00 & 5,00 & 7,00 \\
\hline & A3 & 1,00 & 3,00 & 5,00 & 0,00 & 1,00 & 3,00 & 0,00 & 1,00 & 3,00 & 3,00 & 5,00 & 7,00 & 3,00 & 5,00 & 7,00 & 5,00 & 7,00 & 9,00 & 3,00 & 5,00 & 7,00 \\
\hline & İŞLETMELER & & & & & & & & ARAR & VERIC & $\dot{\mathrm{I}} \mathrm{UZ}$ & MAN & LAR V & IE NC & DTLA & IRI & & & & & & \\
\hline KRITTERELER & & & KV1 & & & KV2 & & & KV3 & & & KV4 & & & KV5 & & & KVe & & & KV7 & \\
\hline & A0 & 0,90 & 1,00 & 1,00 & 0,50 & 0,70 & 0,90 & 0,90 & 1,00 & 1,00 & 0,70 & 0,90 & 1,00 & 0,50 & 0,70 & 0,90 & 0,70 & 0,90 & 1,00 & 0,70 & 0,90 & 1,00 \\
\hline ?. & A1 & 7,00 & 9,00 & 10,00 & 5,00 & 7,00 & 9,00 & 7,00 & 9,00 & 10,00 & 7,00 & 9,00 & 10,00 & 7,00 & 9,00 & 10,00 & 0,00 & 1,00 & 3,00 & 5,00 & 7,00 & 9,00 \\
\hline 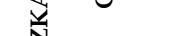 & A2 & 1,00 & 3,00 & 5,00 & 0,00 & 1,00 & 3,00 & 1,00 & 3,00 & 5,00 & 3,00 & 5,00 & 7,00 & 3,00 & 5,00 & 7,00 & 7,00 & 9,00 & 10,00 & 3,00 & 5,00 & 7,00 \\
\hline & A3 & 0,00 & 0,00 & 1,00 & 0,00 & 1,00 & 3,00 & 0,00 & 1,00 & 3,00 & 3,00 & 5,00 & 7,00 & 3,00 & 5,00 & 7,00 & 7,00 & 9,00 & 10,00 & 3,00 & 5,00 & 7,00 \\
\hline & İŞLETMELER & & & & & & & KA & ARAR & VERIC & İ UZ & MAN & LAR V & IE NC & OTLA & ARI & & & & & & \\
\hline KRİTERELER & & & KV1 & & & KV2 & & & KV3 & & & KV4 & & & KV5 & & & KVe & & & KV7 & \\
\hline & A0 & 0,70 & 0,90 & 1,00 & 0,50 & 0,70 & 0,90 & 0,30 & 0,50 & 0,70 & 0,90 & 1,00 & 1,00 & 0,50 & 0,70 & 0,90 & 0,50 & 0,70 & 0,90 & 0,30 & 0,50 & $0,0,70$ \\
\hline$>$ & A1 & 7,00 & 9,00 & 10,00 & 7,00 & 9,00 & 10,00 & 9,00 & 10,00 & 10,00 & 9,00 & 10,00 & 10,00 & 5,00 & 7,00 & 9,00 & 7,00 & 9,00 & 10,00 & 3,00 & 5,00 & 7,00 \\
\hline & A2 & 1,00 & 3,00 & 5,00 & 0,00 & 1,00 & 3,00 & 1,00 & 3,00 & 5,00 & 0,00 & 1,00 & 3,00 & 1,00 & 3,00 & 5,00 & 1,00 & 3,00 & 5,00 & 0,00 & 1,00 & 3,00 \\
\hline 1 & A3 & 1,00 & 3,00 & 5,00 & 0,00 & 1,00 & 3,00 & 1,00 & 3,00 & 5,00 & 0,00 & 0,00 & 1,00 & 1,00 & 3,00 & 5,00 & 1,00 & 3,00 & 5,00 & 3,00 & 5,00 & 7,00 \\
\hline & İŞLETMELER & & & & & & & $\mathbf{K A}$ & ARAR & VERİC & İ UZ & MAN & LAR V & /E NC & DTLA & ARI & & & & & & \\
\hline KRİTERELER & & & KV1 & & & KV2 & & & KV3 & & & KV4 & & & KV5 & & & KVe & & & KV7 & \\
\hline & A0 & 0,50 & 0,70 & 0,90 & 0,70 & 0,90 & 1,00 & 0,30 & 0,50 & 0,70 & 0,70 & 0,90 & 1,00 & 0,50 & 0,70 & 0,90 & 0,90 & 1,00 & 1,00 & 0,30 & 0,50 & 0,70 \\
\hline$\dot{>}$ & $\overline{\mathrm{A} 1}$ & 5,00 & 7,00 & 9,00 & 3,00 & 5,00 & 7,00 & 7,00 & 9,00 & 10,00 & 9,00 & 10,00 & 10,00 & 5,00 & 7,00 & 9,00 & 5,00 & 7,00 & 9,00 & 5,00 & 7,00 & 9,00 \\
\hline & A2 & 1,00 & 3,00 & 5,00 & 1,00 & 3,00 & 5,00 & 1,00 & 3,00 & 5,00 & 5,00 & 7,00 & 9,00 & 3,00 & 5,00 & 7,00 & 3,00 & 5,00 & 7,00 & 0,00 & 1,00 & 3,00 \\
\hline & A3 & 3,00 & 5,00 & 7,00 & 3,00 & 5,00 & 7,00 & 3,00 & 5,00 & 7,00 & 1,00 & 3,00 & 5,00 & 3,00 & 5,00 & 7,00 & 5,00 & 7,00 & 9,00 & 3,00 & 5,00 & 7,00 \\
\hline
\end{tabular}


Tablo 6: (Devam) Karar Vericilerin Değerlendirmelerinin Sayı Karşılıkları

\begin{tabular}{|c|c|c|c|c|c|c|c|c|c|c|c|c|c|c|c|c|c|c|c|c|c|c|}
\hline \multirow{2}{*}{\begin{tabular}{|l|} 
\\
KRITERELER
\end{tabular}} & İSSLETMELER & \multicolumn{21}{|c|}{ KARAR VERICI UZMANLAR VE NOTLARI } \\
\hline & & \multicolumn{3}{|c|}{ KV1 } & \multicolumn{3}{|c|}{ KV2 } & \multicolumn{3}{|c|}{ KV3 } & \multicolumn{3}{|c|}{ KV4 } & \multicolumn{3}{|c|}{ KV5 } & \multicolumn{3}{|c|}{ KV6 } & \multicolumn{3}{|c|}{ KV7 } \\
\hline \multirow{5}{*}{ 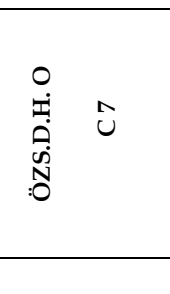 } & A0 & 0,90 & 1,00 & 1,00 & 0,10 & 0,30 & 0,50 & 0,30 & 0,50 & 0,70 & 0,10 & 0,30 & 0,50 & 0,30 & 0,50 & 0,70 & 0,70 & 0,90 & 1,00 & 0,50 & 0,70 & 0,90 \\
\hline & A1 & 0,00 & 1,00 & 3,00 & 5,00 & 7,00 & 9,00 & 3,00 & 5,00 & 7,00 & 9,00 & 10,00 & 10,00 & 1,00 & 3,00 & 5,00 & 0,00 & 1,00 & 3,00 & 1,00 & 3,00 & 5,00 \\
\hline & A2 & 5,00 & 7,00 & 9,00 & 0,00 & 1,00 & 3,00 & 5,00 & 7,00 & 9,00 & 5,00 & 7,00 & 9,00 & 5,00 & 7,00 & 9,00 & 7,00 & 9,00 & 10,00 & 5,00 & 7,00 & 9,00 \\
\hline & $\mathrm{A} 3$ & 7,00 & 9,00 & 10,00 & 0,00 & 1,00 & 3,00 & 5,00 & 7,00 & 9,00 & 0,00 & 1,00 & 3,00 & 5,00 & 7,00 & 9,00 & 9,00 & 10,00 & 10,00 & 5,00 & 7,00 & 9,00 \\
\hline & IŞLETMELER & \multicolumn{21}{|c|}{ KARAR VERİCI UZMANLAR VE NOTLARI } \\
\hline KRITEERELER & & \multicolumn{3}{|c|}{ KV1 } & \multicolumn{3}{|c|}{ KV2 } & \multicolumn{3}{|c|}{ KV3 } & \multicolumn{3}{|c|}{ KV4 } & \multicolumn{3}{|c|}{ KV5 } & \multicolumn{3}{|c|}{ KV6 } & \multicolumn{3}{|c|}{ KV7 } \\
\hline \multirow{5}{*}{ 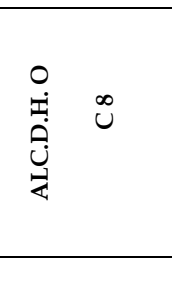 } & A0 & 0,30 & 0,50 & 0,70 & 0,50 & 0,70 & 0,90 & 0,90 & 1,00 & 1,00 & 0,30 & 0,50 & 0,70 & 0 & 0,90 & 1,00 & 0,70 & 0,90 & 1,00 & 0,70 & 0,90 & 1,00 \\
\hline & A1 & 3,00 & 5,00 & 7,00 & 1,00 & 3,00 & 5,00 & 1,00 & 3,00 & 5,00 & 7,00 & 9,00 & 10,00 & 3,00 & 5,00 & 7,00 & 3,00 & 5,00 & 7,00 & 1,00 & 3,00 & 5,00 \\
\hline & $\mathrm{A} 2$ & 1,00 & 3,00 & 5,00 & 3,00 & 5,00 & 7,00 & 3,00 & 5,00 & 7,00 & 3,00 & 5,00 & 7,00 & 3,00 & 5,00 & 7,00 & 3,00 & 5,00 & 7,00 & 1,00 & 3,00 & 5,00 \\
\hline & $\mathrm{A} 3$ & 7,00 & 9,00 & 10,00 & 5,00 & 7,00 & 9,00 & 3,00 & 5,00 & 7,00 & 7,00 & 9,00 & 10,00 & 5,00 & 7,00 & 9,00 & 5,00 & 7,00 & 9,00 & 7,00 & \begin{tabular}{l|l}
, 00 &
\end{tabular} & 10,00 \\
\hline & İ̧̧LETMELER & \multicolumn{21}{|c|}{ KARAR VERÍCI UZMANLAR VE NOTLARI } \\
\hline KRITERELER & & \multicolumn{3}{|c|}{ KV1 } & & KV2 & & & KV3 & & & KV4 & & & KV5 & & & KV6 & & & KV7 & \\
\hline & A0 & 0,50 & 0,70 & 0,90 & 0,50 & 0,70 & 0,90 & 0,90 & 1,00 & 1,00 & 0,00 & 0,10 & 0,30 & $0,0,70$ & \begin{tabular}{|l|}
0,90 \\
\end{tabular} & 1,00 & 0,50 & 0,70 & 0,90 & 0,70 & \begin{tabular}{|l|l}
0,90 \\
\end{tabular} & 1,00 \\
\hline$\underline{0}$ & $\mathrm{~A} 1$ & 3,00 & 5,00 & 7,00 & 3,00 & 5,00 & 7,00 & 3,00 & 5,00 & 7,00 & 9,00 & 10,00 & \begin{tabular}{|l|}
10,00 \\
\end{tabular} & 7,000 & 9,00 & \begin{tabular}{|l|}
10,00 \\
\end{tabular} & 7,000 & 9,00 & \begin{tabular}{l|l|}
10,00 \\
\end{tabular} & 7,00 & \begin{tabular}{|l|l}
9,00 & \\
\end{tabular} & 10,00 \\
\hline$\stackrel{\dot{g}}{ }$ & A2 & 0,00 & 0,00 & 1,00 & 1,00 & 3,00 & 5,00 & 1,00 & 3,00 & 5,00 & 1,00 & 3,00 & 5,00 & 1,00 & 3,00 & 5,00 & 3,00 & 5,00 & 7,00 & 1,00 & 3,00 & 5,00 \\
\hline & A3 & 9,00 & 10,00 & 10,00 & 7,00 & 9,00 & 10,00 & 5,00 & 7,00 & 9,00 & 7,00 & 9,00 & 10,00 & 7,00 & \begin{tabular}{|l|l}
9,00 & 1 \\
\end{tabular} & 10,00 & 7,00 & 9,00 & 10,00 & 7,00 & 9,00 & 10,00 \\
\hline & İŞLETMELER & & & & & & & & & & ARAR & R VERII & ici UZI & MANL & LAR VE & ENOT & TLARI & & & & & \\
\hline KRITERELER & & & KV1 & & & $\mathrm{KV}_{2}$ & & & KV3 & & & KV4 & & & KV5 & & & KV6 & & & KV7 & \\
\hline & A0 & 0,90 & 1,00 & 1,00 & 0,70 & 0,90 & 1,00 & 0,70 & 0,90 & 1,00 & 0,00 & 0,10 & 0,30 & 0,90 & 1,00 & 1,00 & 0,90 & $\begin{array}{ll}1,00 \\
\end{array}$ & 1,00 & 0,50 & 0,70 & 0,90 \\
\hline $\begin{array}{l}0 \\
\text { N }\end{array}$ & A1 & 5,00 & 7,00 & 9,00 & 1,00 & 3,00 & 5,00 & 3,00 & 5,00 & 7,00 & 9,00 & 10,00 & 10,00 & 7,00 & 9,00 & 10,00 & 3,00 & \begin{tabular}{|l|l|}
5,00 \\
\end{tabular} & 7,00 & 5,00 & 7,00 & 9,00 \\
\hline 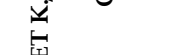 & A2 & 0,00 & 0,00 & 1,00 & 0,00 & 1,00 & 3,00 & 0,00 & 1,00 & 3,00 & 0,00 & 0,00 & 1,00 & 0,00 & 1,00 & 3,00 & 0,00 & \begin{tabular}{|l|l|} 
& 1,00 \\
\end{tabular} & 3,00 & 3,00 & 5,00 & 7,00 \\
\hline & A3 & 9,00 & 10,00 & 10,00 & 7,00 & 9,00 & 10,00 & 3,00 & 5,00 & 7,00 & 9,00 & 10,00 & 10,00 & 7,00 & 9,00 & 10,00 & 7,00 & \begin{tabular}{|l|l|} 
& 9,00 \\
\end{tabular} & 10,00 & 7,00 & 9,00 & 10,00 \\
\hline & İŞLETMELER & & & & & & & KAI & RAR & VERİ & Ċं U & JZMAI & NLAR & 2 VE N & NOTL & LARI & & & & & & \\
\hline KRITERELER & & & $\mathrm{KV} 1$ & & & $\mathrm{KV}_{2}$ & & & KV3 & & & KV4 & & & KV5 & & & KV6 & & & KV7 & \\
\hline & A0 & 0,90 & 1,00 & 1,00 & 0,70 & 0,90 & 1,00 & 0,50 & 0,70 & 0,90 & 0,10 & 0,30 & 0,50 & 0,90 & 1,00 & 1,00 & 0,90 & 1,00 & 1,00 & 0,50 & 0,70 & 0,90 \\
\hline $\begin{array}{l}0 \\
\dot{\sim}\end{array}$ & A1 & 5,00 & $\begin{array}{l}7,00 \\
\end{array}$ & 9,00 & $5,5,00$ & 7,00 & 9,00 & 3,00 & 5,00 & 7,00 & $\begin{array}{l}9,00 \\
\end{array}$ & 10,00 & 10,00 & 7,00 & 9,00 & $\mid 10,00$ & 7,00 & 9,00 & $\mid \begin{array}{l}\mid 10,00 \\
\end{array}$ & 7,00 & $\begin{array}{l}9,00 \\
\end{array}$ & 10,00 \\
\hline : & A2 & 0,00 & \begin{tabular}{|l|l|} 
& 0,00
\end{tabular} & 1,00 & 1,00 & $\begin{array}{l}3,00 \\
\end{array}$ & 5,00 & 0 & 1,00 & 3,00 & \begin{tabular}{|l|l|} 
& 0,00 \\
\end{tabular} & 1,00 & 3,00 & \begin{tabular}{|l|l|}
1,00 \\
\end{tabular} & 3,00 & 5,00 & 0,00 & 1,00 & \begin{tabular}{|l|l|}
3,00 \\
\end{tabular} & 1,00 & 3,00 & 5,00 \\
\hline & A3 & 3,00 & $\begin{array}{l}5,00 \\
\end{array}$ & 7,00 & 3,00 & 5,00 & 7,00 & 1,00 & 3,00 & 5,00 & 7,00 & 9,00 & 10,00 & 5,00 & 7,00 & 9,00 & 5,00 & 7,00 & 9 & 5,00 & 7,00 & 9,00 \\
\hline
\end{tabular}


Tablo 6: (Devam) Karar Vericilerin Değerlendirmelerinin Sayı Karşılıkları

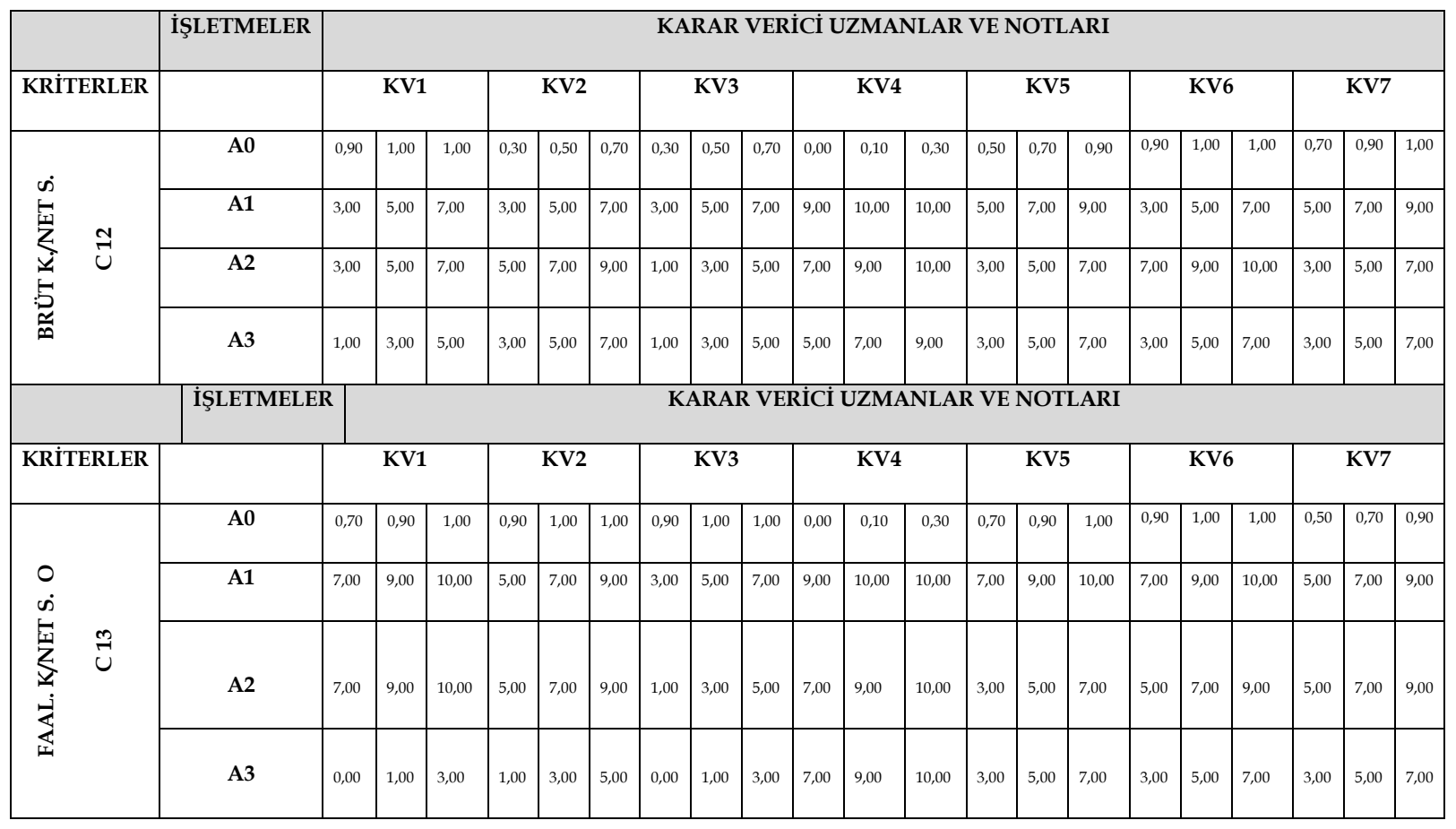

Tablo 7: Kriter Ağırlıkları (A0)

\begin{tabular}{|c|c|c|c|}
\hline & \multicolumn{3}{|c|}{ Kriter Ağırlıları(A0) } \\
\hline Kriterler & & 0,69 & 0,83 \\
\hline Cari Oran & 0,50 & 0,76 & 0,87 \\
\hline Asit-Test Oranı & 0,59 & 0,86 & 0,97 \\
\hline TV/TB Oranı & 0,67 & 0,73 & 0,97 \\
\hline ÖZ/TB Oranı & 0,70 & 0,71 & 0,87 \\
\hline KVYK/TV Oranı & 0,53 & 0,74 & 0,89 \\
\hline UVYK/TV Oranı & 0,56 & 0,60 & 0,76 \\
\hline ÖZS.D.H. & 0,41 & 0,77 & 0,90 \\
\hline ALACAK D.H. & 0,59 & 0,71 & 0,86 \\
\hline STOK D.H. & 0,54 & 0,80 & 0,89 \\
\hline NET K./ÖZS. Oranı & 0,66 & 0,80 & 0,90 \\
\hline AKT. KAR Oranı & 0,64 & 0,67 & 0,80 \\
\hline BRÜT S.K/NET S. Oranı & 0,51 & 0,80 & 0,89 \\
\hline FAALİYET K./NET S. Oranı & 0,66 & & \\
\hline
\end{tabular}


Adım 3: Bulanık Karar Matrisinin Oluşturulması

Bulanık karar matrisini oluşturmak için (3) nolu formülü kullanılır.

Tablo 8: Bulanik Karar Matrisi

\begin{tabular}{|c|c|c|c|c|c|c|c|c|c|c|c|c|c|c|c|c|c|c|c|c|c|}
\hline & \multicolumn{3}{|c|}{ C 1} & \multicolumn{3}{|c|}{ C 2} & \multicolumn{3}{|c|}{ C 3} & \multicolumn{3}{|c|}{ C 4} & \multicolumn{3}{|c|}{ C 5} & \multicolumn{3}{|c|}{ C 6} & \multicolumn{3}{|c|}{ C 7} \\
\hline A 1 & 8,43 & 9,71 & 10,00 & 7,86 & 9,29 & 9,86 & 5,57 & 7,43 & 8,86 & 5,43 & 7,29 & 8,71 & 6,71 & 8,43 & 9,43 & 5,57 & 7,43 & 9,00 & 2,71 & 4,29 & 6,00 \\
\hline A 2 & 2,43 & 4,43 & 6,43 & 1,57 & 3,29 & 5,29 & 2,29 & 4,14 & 6,14 & 2,57 & 4,43 & 6,29 & 0,57 & 2,14 & 4,14 & 2,00 & 3,86 & 5,86 & 4,57 & 6,43 & 8,29 \\
\hline \multirow[t]{2}{*}{ A 3} & 1,57 & 3,29 & 5,29 & 1,57 & 3,29 & 5,29 & 2,14 & 3,86 & 5,86 & 2,29 & 3,71 & 5,43 & 1,00 & 2,57 & 4,43 & 3,00 & 5,00 & 7,00 & 4,43 & 6,00 & 7,57 \\
\hline & \multicolumn{3}{|c|}{ C 8} & \multicolumn{3}{|c|}{ C9 } & \multicolumn{3}{|c|}{ C 10} & \multicolumn{3}{|c|}{ C 11} & \multicolumn{3}{|c|}{ C 12} & \multicolumn{3}{|c|}{ C 13} & & & \\
\hline A 1 & 2,71 & 4,71 & 6,57 & 5,57 & 7,43 & 8,71 & 4,71 & 6,57 & 8,14 & 6,14 & 8,00 & 9,29 & 4,43 & 6,29 & 8,00 & 6,14 & 8,00 & 9,29 & & & \\
\hline A 2 & 2,43 & 4,43 & 6,43 & 1,14 & 2,86 & 4,71 & 0,43 & 1,29 & 3,00 & 0,43 & 1,71 & 3,57 & 4,14 & 6,14 & 7,86 & 4,71 & 6,71 & 8,43 & & & \\
\hline A 3 & 5,57 & 7,57 & 9,14 & 7,00 & 8,86 & 9,86 & 7,00 & 8,71 & 9,57 & 4,14 & 6,14 & 8,00 & 2,71 & 4,71 & 6,71 & 2,43 & 4,14 & 6,00 & & & \\
\hline
\end{tabular}

Adım 4: Normalize Bulanık Karar Matrisinin Oluşturulması

Bu aşamada (4) nolu formül kullanılarak Normalize edilmiş bulanık karar matrisi oluşturulur.

Tablo 9: Normalize Bulanık Karar Matrisi

\begin{tabular}{|c|c|c|c|c|c|c|c|c|c|c|c|c|c|c|c|c|c|c|c|c|c|}
\hline & \multicolumn{3}{|c|}{ C 1} & \multicolumn{3}{|c|}{ C 2} & \multicolumn{3}{|c|}{ C 3} & \multicolumn{3}{|c|}{ C 4} & \multicolumn{3}{|c|}{ C 5} & \multicolumn{3}{|c|}{ C 6} & \multicolumn{3}{|c|}{ C 7} \\
\hline A 1 & 0,84 & 0,97 & 1,00 & 0,80 & 0,94 & 1,00 & 0,63 & 0,84 & 1,00 & 0,62 & 0,84 & 1,00 & 0,71 & 0,89 & 1,00 & 0,62 & 0,83 & 1,00 & 0,33 & 0,52 & 0,72 \\
\hline A 2 & 0,24 & 0,44 & 0,64 & 0,16 & 0,33 & 0,54 & 0,26 & 0,47 & 0,69 & 0,30 & 0,51 & 0,72 & 0,06 & 0,23 & 0,44 & 0,22 & 0,43 & 0,65 & 0,55 & 0,78 & 1,00 \\
\hline \multirow[t]{2}{*}{ A 3} & 0,16 & 0,33 & 0,53 & 0,16 & 0,33 & 0,54 & 0,24 & 0,44 & 0,66 & 0,26 & 0,43 & 0,62 & 0,11 & 0,27 & 0,47 & 0,33 & 0,56 & 0,78 & 0,53 & 0,72 & 0,91 \\
\hline & \multicolumn{3}{|c|}{ C 8} & \multicolumn{3}{|c|}{ C 9} & \multicolumn{3}{|c|}{ C 10} & \multicolumn{3}{|c|}{ C 11} & \multicolumn{3}{|c|}{ C 12} & \multicolumn{3}{|c|}{ C 13} & & & \\
\hline A 1 & 0,30 & 0,52 & 0,72 & 0,57 & 0,75 & 0,88 & 0,49 & 0,69 & 0,85 & 0,66 & 0,86 & 1,00 & 0,55 & 0,79 & 1,00 & 0,66 & 0,86 & 1,00 & & & \\
\hline A 2 & 0,27 & 0,48 & 0,70 & 0,12 & 0,29 & 0,48 & 0,04 & 0,13 & 0,31 & 0,05 & 0,18 & 0,38 & 0,52 & 0,77 & 0,98 & 0,51 & 0,72 & 0,91 & & & \\
\hline A 3 & 0,61 & 0,83 & 1,00 & 0,71 & 0,90 & 1,00 & 0,73 & 0,91 & 1,00 & 0,45 & 0,66 & 0,86 & 0,34 & 0,59 & 0,84 & 0,26 & 0,45 & 0,65 & & & \\
\hline
\end{tabular}

Adım 5: Ağırlıklandırılmış Normalize Bulanık Karar Matrisinin Oluşturulması

Ağırlıklandırılmış Normalize Bulanık Karar Matrisi (5) ve (6) nolu formüllerden yararlanarak hazırlanmaktadır.

Tablo 10: Ağırlıklandırılmış Normalize Bulanık Karar Matrisi

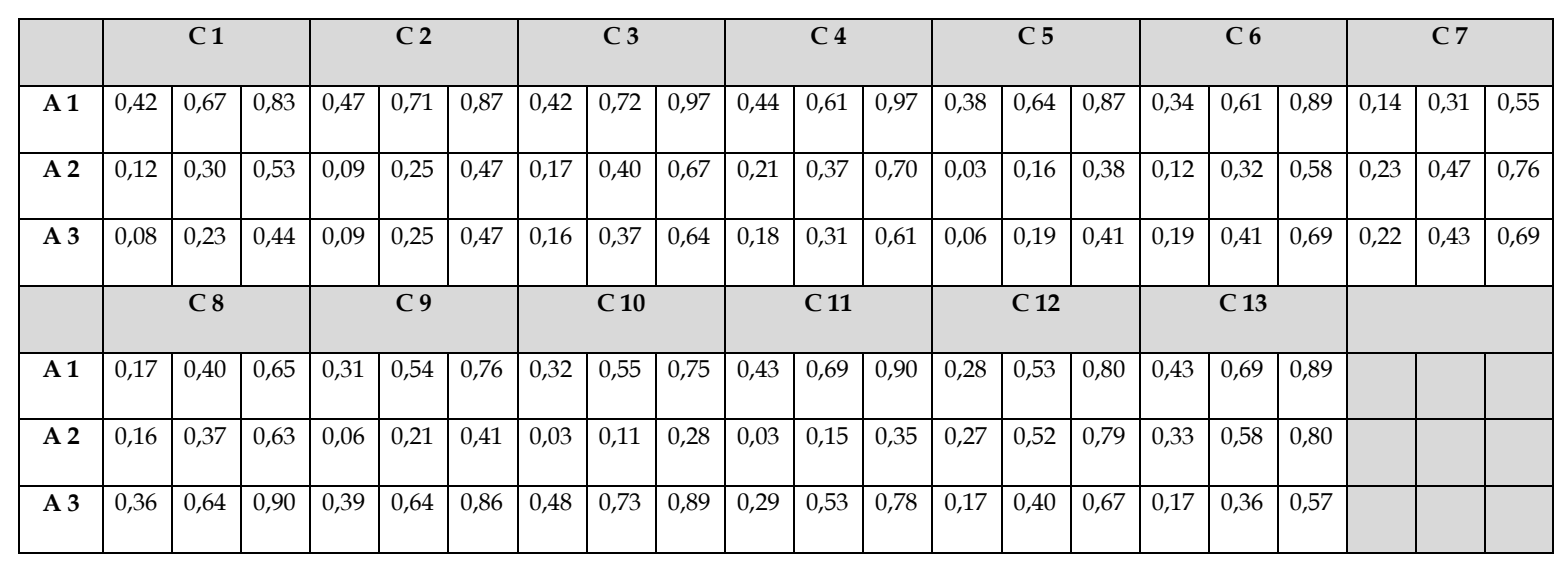


Adım 6 ve 7: Pozitif ve Negatif İdeal Çözümlerin Hesaplanması

Tablo 11: Pozitif İdeal Çözüm (FPİ̧̧)

\begin{tabular}{|c|c|c|c|c|c|c|c|c|c|c|c|c|c|}
\hline D+(M,N) & C 1 & C 2 & C 3 & C 4 & C 5 & C 6 & C 7 & C 8 & C 9 & C 10 & C 11 & C 12 & C 13 \\
\hline A 1 & 0,40 & 0,36 & 0,37 & 0,40 & 0,42 & 0,44 & 0,69 & 0,62 & 0,50 & 0,49 & 0,38 & 0,51 & 0,38 \\
\hline A 2 & 0,70 & 0,74 & 0,62 & 0,61 & 0,82 & 0,69 & 0,56 & 0,64 & 0,79 & 0,87 & 0,84 & 0,52 & 0,47 \\
\hline A 3 & 0,77 & 0,74 & 0,64 & 0,66 & 0,79 & 0,61 & 0,58 & 0,43 & 0,42 & 0,34 & 0,51 & 0,62 & 0,65 \\
\hline
\end{tabular}

Tablo 12: Negatif İdeal Çözüm (FNiç)

\begin{tabular}{|c|c|c|c|c|c|c|c|c|c|c|c|c|c|}
\hline D-(M,N) & C 1 & C 2 & C 3 & C 4 & C 5 & C 6 & C 7 & C 8 & C 9 & C 10 & C 11 & C 12 & C 13 \\
\hline A 1 & 0,66 & 0,70 & 0,74 & 0,71 & 0,66 & 0,65 & 0,37 & 0,45 & 0,57 & 0,57 & 0,70 & 0,58 & 0,69 \\
\hline A 2 & 0,36 & 0,31 & 0,46 & 0,47 & 0,24 & 0,39 & 0,53 & 0,43 & 0,27 & 0,17 & 0,22 & 0,56 & 0,60 \\
\hline A 3 & 0,29 & 0,31 & 0,44 & 0,41 & 0,26 & 0,48 & 0,49 & 0,67 & 0,66 & 0,72 & 0,57 & 0,46 & 0,40 \\
\hline
\end{tabular}

Adım 8: Alternatiflerin FPIÇ ve FNIÇ̧ ten Uzaklıklarının Hesaplanması

Tablo 13: Alternatiflerin FPİç ve FNIÇ'ten Uzaklıkları

\begin{tabular}{|c|c|c|c|}
\hline D+ & & D- & \\
\hline A1 & 5,96 & A1 & 8,05 \\
\hline A2 & 8,87 & A2 & 5,03 \\
\hline A3 & 7,77 & A3 & 6,15 \\
\hline
\end{tabular}

Adım 9: Alternatiflerin Yakınlık Katsayısının Hesaplanması

$$
\begin{aligned}
& C C_{0}=\frac{8,05}{8,05+5,96}=0,57 \\
& C C_{0}=\frac{5,03}{5,03+8,87}=0,36 \\
& C C_{0}=\frac{6,15}{6,15+7,77}=0,44
\end{aligned}
$$

Adım 10: Yakınlık Katsayılarına Göre Sıralamanın Oluşturulması

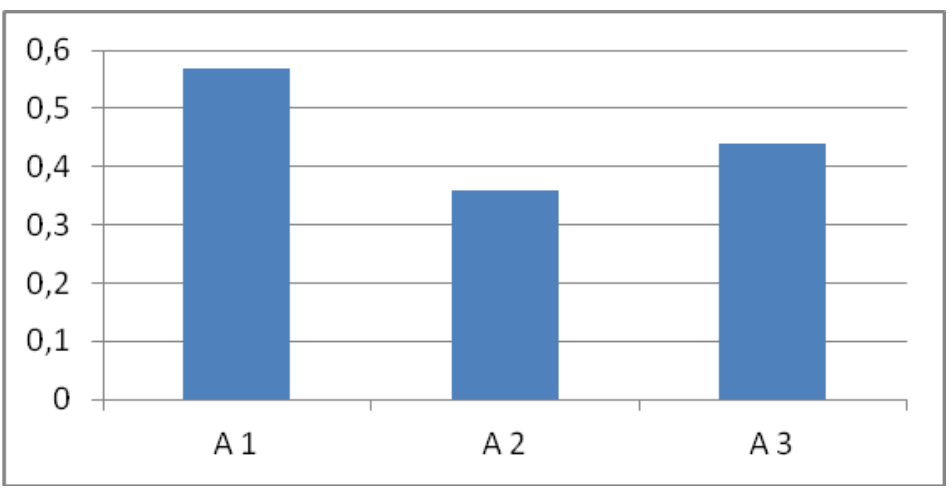

Şekil 2: Yakınlık Katsayısına Göre Sıralama 


\section{Sonuç}

Karar verme, bireyin, yöneticinin, yatırımcının ya da örgütün seçenekler arasından en uygununu belirlemesidir. Karar verme işlevi her zaman hayatımızda karşımıza çıkmaktadır.

Birden fazla karar vericinin yer aldığı grup karar vermede, çok sayıda karar kriterine göre pek çok alternatif arasından seçim yapılması gerektiğinde karar verme daha da zor bir hale gelmektedir. Çünkü grup kararı verilirken, grup içerisinde yer alan üyeler arasında düşünce ayrılıkları yaşanabilmektedir. Bu nedenle birçok karar vericinin olduğu ve karar vermedeki zorluğu azaltmak için Çok Kriterli Karar Verme Yöntemlerinden yararlanılmaktadır. Bulanık TOPSIS yöntemi ise, belirsizliğin neden olduğu durumlarda yaygın kullanılan Çok Kriterli Karar Verme Yöntemlerinden bir tanesidir.

Çalışmada Bulanık TOPSIS yöntemi ile Borsada işlem gören savunma sanayi şirketlerinin finansal performanslarını ölçmeye yönelik bir uygulama yapılarak bununla birlikte Bulanık TOPSIS yönteminin işleyişini açıklamaya çalışılmıştır. Bulanık TOPSIS yöntemi sayesinde karar verme sürecinin daha da kolay bir hale geldiği, belirsizliğin ortadan kalktığı ve daha doğru kararlar verildiğini söylemek yanlış olmayacaktır.

Sonuç olarak, bu çalışmada 13 kriter dikkate alınarak 3 savunma işletmesinin performans değerlendirmesi gerçekleştirilmiştir. Bulanık TOPSIS analizi sonucu performans bakımından Aselsan Elektronik Sanayi ve Ticaret A.Ş. birinci, Otokar Otomotiv Savunma Sanayi A.Ş. ikinci, Katmerciler Araç Üstü Ekipman Sanayi ve Ticaret A.Ş. sonuncu olmuştur.

Aselsan'ın finansal oranları incelendiğinde son on (10) yılda olumlu yönde sürekli artış göstermiştir. İşletme satışlarının \%90'ını ülke içine yapmaktadır. Bu da şirketin iç pazarda önemli bir paya sahip olduğunu ve iç pazardaki satışlarından da önemli bir gelir elde ettiğini göstermektedir. Bununla birlikte, araştırmaya dahil edilen şirketler ile karşılaştırıldığında Aselsan'ın kaldıraç oranı \%40$50^{\prime}$ lerde seyrederken diğer iki şirketin kaldıraç oranı \%70-80'lerdedir. Şirket borçluluğunu gösteren bu oranın yüksek olması şirketler için risklidir. Dolaysıyla bu anlamda da Aselsan diğer iki şirkete göre finansman riski bakımından daha iyi durumdadır. Asit Test, Kısa Vadeli Yabanc1 Kaynaklar, Net Karlılık, Aktif Karlılık oranlarının diğer işletmelere göre iyi olması da Aselsan'ı bir adım öne çıkarmaktadır. Aynı zamanda şirketin elde ettiği karları hisse sahiplerine belirli ölçüde dağıtması ve bir kısmının yeni yatırımlar için finansman olarak ayrılması da işletmenin kaynak sıkıntısı çekmemesini sağlamaktadır. Şirketlerin mali tablolarından elde edilen verilere bakıldığında da Aselsan'ın daha sağlıklı bir finansal yapıya sahip olduğu gözlenmektedir. Bu değerlendirmeler aslında Bulanık TOPSIS yöntemi ile elde ettiğimiz sonuçlar ile uyumludur.

Ancak çalışmada kullanılan şirketlerin şu anki borsa performansları ele alındığında hisse fiyatı olarak Otokar birinci sırada, Aselsan ikinci sırada, Katmercilerin ise son sırada olduğu görülmektedir. Çalışmamızda elde ettiğimiz sonuçlar Aselsan'ın finansal kriterlere göre daha değerli olduğunu gösterse de şu anki piyasa koşullarında yatırımcı değerlendirmesi bu şekilde oluşmamıştır. Beklentimiz önümüzdeki süreçte şirketin finansal gerçeklerinin ve değerinin borsa performansına yansımasıdır. Bu açıdan bakıldı̆̆ında Bulanık TOPSIS yöntemi aslında yatırımcılara bir Temel Analiz yapma imkânı sunmaktadır. Dolayısıyla bu çalışma literatüre yapacağı katkının yanında hisse senedi yatırımcıları içinde farklı bir bakış açısı getirmeyi de hedeflemektedir. Bu bakış açısı bundan sonraki çalışmalar içinde bir başlangıç olabilir.

Savunma sanayi üzerinde bu yöntem kullanılarak yapılan çalışmaların yetersizliği nedeniyle, çalışmanın sonuçlarının başka çalışmaların sonuçlarıyla kıyaslanması noktasında bir değerlendirme yapilamamıştır.

Bu çalışma doğrultusunda ilerde daha çok savunma sanayi alanında faaliyet gösteren şirketleri ya da başka alanlarda faaliyet gösteren işletmeleri analize dahil ederek, yatırım yapacak potansiyel yatırımcılara yatırım analizleri noktasında katkı sağlanabilecektir. Bu anlamda, bulanık TOPSIS yönteminin diğer sektörlerde faaliyet gösteren işletmelerin performanslarının bu açıdan da değerlendirilmesinde kullanılması uygun bir yöntem olduğu söylenebilir.

\section{Hakem Değerlendirmesi / Peer-review:}

Disş bağımsız

Externally peer-reviewed 


\section{Çıkar Çatışması / Conflict of interests:}

Yazar(lar) çıkar çatışması bildirmemiştir.

The author(s) has (have) no conflict of interest to declare.

\section{Finansal Destek/ Grant Support:}

Yazar bu çalışma için finansal destek almadı̆̆ını beyan etmiştir.

The author declared that this study has received no financial support.

\section{Kaynakça / References}

Kayalı, C , Aktaş, İ . (2018). BİST’te Hisse Senetleri İşlem Gören Otomotiv Sektöründeki Firmaların TOPSIS Yöntemine Göre Performans Değerlemesi ve Analizi1 . Karabük Üniversitesi Sosyal Bilimler Enstitüsü Dergisi , 8 (1) , 43-59 . Retrieved from https://dergipark.org.tr/en/pub/ joiss/issue/47347/597390

Bakır, G. (2019). İnsansız Hava Araçlarının Savunma sanayi Harcamasında Yeri ve Önemi. Avrasya Sosyal ve Ekonomik Araştırmalar Dergisi, 6(2), 127-134 Retrieved from https:/ / dergipark.org.tr/ en/pub/asead/issue/43544/526954

Borsaİstanbul.(2019). https://www.borsaistanbul.com/kurumsal/borsa-istanbul-hakında. (Erişim Tarihi:6.10.2019).

Bilici, N. (2019). Turizm Sektörünün Finansal Performansının Oran Analizi ve TOPSIS Yöntemiyle Değerlendirilmesi. Atatürk Üniversitesi Sosyal Bilimler Enstitüsü Dergisi, 23(1), 173-194. Retrieved from https://dergipark.org.tr/en/pub/ataunisosbil/issue/43928/538474

Chen, C. (2001). A Fuzzy Approach to Select the Location of the Distribution Center. Fuzzy Sets and Systems, 118(23), 65-73. https:/ / doi.org/10.1016/S0165-0114(98)00459-X.

Chen, C. T. (2000). Extensions of the TOPSIS for Group Decision-Making under Fuzzy Environment. Fuzzy Sets and Systems, 114(20), 1-9. https:/ / doi.org/10.1016/S0165-0114(97)00377-1

Demirhan, D , Aracıoğlu, B . (2017). İnovasyon Ve Finansal Performans Arasındaki İlişki: BİST Teknoloji Endeksindeki Firmalar Üzerine Bir Araştırma . Uluslararası İktisadi ve İdari İncelemeler Dergisi , 16. UIK Special Issue , 195-218 . DOI: 10.18092/ulikidince.323730

Değer, S. (1986). Economic Development and Defense Expenditure. Economic Development and Cultural Change, 35(1), 179-196.

Dündar, S., Ecer, F. ve Özdemir, Ş. (2007). Fuzzy Topsis Yöntemi İle Sanal Mağazalarin Web Sitelerinin Değerlendirilmesi. Atatürk Üniversitesi İktisadi ve İdari Bilimler Dergisi, 21(1), 287-305. Retrieved from https:/ / dergipark.org.tr/en/pub/atauniiibd/issue/2691/35409

Ecer, F. (2006). Bulanık Ortalamalarda Grup Kararı Vermeye Yardımcı Bir Yöntem: Fuzzy TOPSIS ve Bir Uygulama. Dokuz Eylül Üniversitesi İşletme Fakültesi Dergisi 7 (2), 77-96. Retrieved from https://dergipark.org.tr/en/pub/ifede/issue/4601/62873

Ecer, F. (2007). Satış Elemenı Adaylarının Değerlendirilmesine ve Seçiimine Yönelik Yeni Bir Yaklaşım: Fuzzy TOPSİS. Anadolu University Joumal of Social Scences 7 (2), 187-204.

Gürbüz, O. ve Engincan, Y. (2004). Şirket Değerlemesi - Klasik ve Modern Yaklaşımlar. Istabul: Literatür Yayımcilık 2004.

Janko, W., \& Bemroider, E. (2005). Multi- Criteria Decision Making: An Application Study of ELECTRE And TOPSIS, 1-36. http:/ / www.wu-wien.ac.at/-bernroid/seminare/ws04/ A7-TOPSIS0107503.pdf (Erişim Tarihi:12.11.2019). 
Karcıoğlu, R , Yalçın, S , Gültekïn, Ö . (2020). Sezgisel Bulanık Mantık ve Entropi Tabanlı Çok Kriterli Karar Verme Yöntemiyle Finansal Performans Analizi: BİST'de İşlem Gören Enerji Şirketleri Üzerine Bir Uygulama . MANAS Sosyal Araştırmalar Dergisi , 9 (1) , 360-372 . DOI: $10.33206 /$ mjss.535211

Konukbay, A. (2016). Ankara'da Savunma Teknolojilerinde Faaliyet Gösteren Kobilerin Açık Yenilik Yaklaşımlarının Değerlendirilmesi. Gazi Mühendislik Bilimleri Dergisi (GMBD), 2(1), 53-76. Retrieved from https:// dergipark.org.tr/en/pub/gmbd/issue/29243/313089

Özçelik, H , Küçükçakal, Z . (2019). BIST'de İşlem Gören Finansal Kiralama ve Faktoring Şirketlerinin Finansal Performanslarının TOPSIS Yöntemi İle Analizi . Muhasebe ve Finansman Dergisi , (81), 249-270 . DOI: 10.25095/mufad.510675

E.saygılı, E , Şahin, Y . (2018). Finansal Performans İle Hisse Senedi Yatırımcı Kararları Arasındaki İlişki: Bıst Çimento Sektöründe Topsıs Uygulaması . Izmir Democracy University Social Sciences Journal , 1 (1) , 16-45 . Retrieved from https://dergipark.org.tr/en/pub/idusos/issue/37793/ 379995

Savunma Sanayi Dergilik, (2020). https://www.savunmasanayiidergilik.com/tr/Haber Dergilik/ Savunmada- hedef-yerliliğ̈i-ve-istihdamı-artırmak. (Erişim Tarihi:19.11.2020).

Şişman, D. (2017). Küreselleşme, Kriz ve Savunma Sanayi. Marmara Üniversitesi İktisadi ve İdari Bilimler Dergisi, 39(1), 223-237. DOI: 10.14780/muiibd.329928

Temiz, D. (2012) Ekonomin Önemli Bir Parçası: Savunma Sanayi. Dumlupınar Üniversitesi Sosyal Bilimler Dergisi, 1(33), 1-18. Retrieved from https://dergipark.org.tr/en/ pub/dpusbe/ issue $/ 4775 / 65763$

Tezcan, N . (2019). İşletmelerde Finansal Performans ve İhracat Düzeyi Arasındaki İlişki: Türkiye Otomotiv Sanayi Örneği . Çağ Üniversitesi Sosyal Bilimler Dergisi , 16 (2) , 87-101 . Retrieved from https://dergipark.org.tr/en/pub/cagsbd/issue/51317/668655

Topçu, M. K. (2010) Savunma Planlamasının Ekonomiye Etkileri ve Savunma Bütçeleri. Savunma Bilimler Dergisi, 1(9), 75-96. Retrieved from https://dergipark.org.tr/en/pub/ khosbd/ issue/19228/204326

Topal, B. G. (2020). Türkiye'de Terör Eylemleri ve Savunma Sanayi İlişkisi. Fırat Üniversitesi Uluslararast İktisadi ve İdari Bilimler Dergisi, 4(1), 51-86. Retrieved from https://dergipark.org.tr/ en/pub/fuuiibfdergi/issue/54867/712904

Yeşilyurt, F , Yeşilyurt, M . (2019). Türkiye'de Savunma Sanayi . Pamukkale Journal of Eurasian Socioeconomic Studies , 6 (2) , 1-42 . DOI: 10.34232/ pjess.565105

Yıldız, B. (2013). Sağlık İşletmelerinde Finansal Performansı Etkileyen Unsurlar ve Finansal Performansın Ölçülmesi: Hastanelerde bir Uygulama. Yayınlanmamış Doktora Tezi. Atatürk Üniversitesi Sosyal Bilimler Enstitüsü,Erzurum. 